\title{
Using radiometric surface temperature for surface energy flux estimation in Mediterranean drylands from a two-source perspective
}

Morillas, L.; Garcia Garcia, Monica; Nieto Solana, Hector; Villagarcia, L.; Sandholt, Inge; Gonzalez-Dugo, M.P.; Zarco-Tejada, P.J.; Domingo, F.

Published in:

Remote Sensing of Environment

DOI:

10.1016/j.rse.2013.05.010

Publication date:

2013

Document version

Peer reviewed version

Citation for published version (APA):

Morillas, L., Garcia Garcia, M., Nieto Solana, H., Villagarcia, L., Sandholt, I., Gonzalez-Dugo, M. P., Zarco-

Tejada, P. J., \& Domingo, F. (2013). Using radiometric surface temperature for surface energy flux estimation in Mediterranean drylands from a two-source perspective. Remote Sensing of Environment, 136, $234-246$. https://doi.org/10.1016/j.rse.2013.05.010 
Provided for non-commercial research and education use. Not for reproduction, distribution or commercial use.

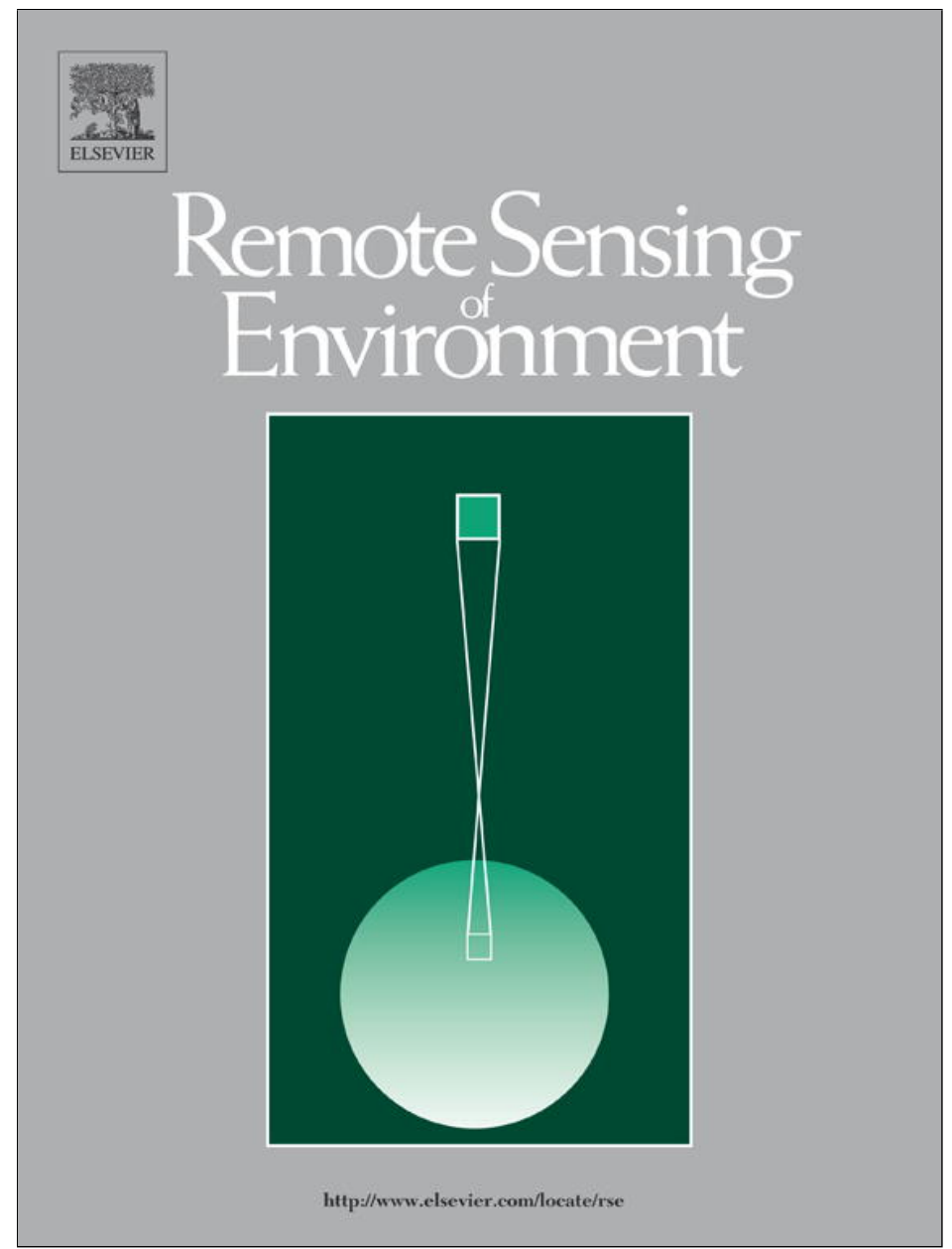

This article appeared in a journal published by Elsevier. The attached copy is furnished to the author for internal non-commercial research and education use, including for instruction at the authors institution and sharing with colleagues.

Other uses, including reproduction and distribution, or selling or licensing copies, or posting to personal, institutional or third party websites are prohibited.

In most cases authors are permitted to post their version of the article (e.g. in Word or Tex form) to their personal website or institutional repository. Authors requiring further information regarding Elsevier's archiving and manuscript policies are encouraged to visit:

http://www.elsevier.com/authorsrights 


\title{
Using radiometric surface temperature for surface energy flux estimation in Mediterranean drylands from a two-source perspective
}

\author{
L. Morillas ${ }^{\text {a,* }}$, M. García ${ }^{\text {b,c }}$, H. Nieto $^{\text {b }}$, L. Villagarcia ${ }^{\text {d }}$, I. Sandholt ${ }^{\text {b }}$, M.P. Gonzalez-Dugo ${ }^{\text {e, }}$ \\ P.J. Zarco-Tejada ${ }^{\text {f }}$, F. Domingo ${ }^{\text {a }}$ \\ a Estación Experimental de Zonas Áridas, Consejo Superior de Investigaciones Científicas (CSIC), Ctra. de Sacramento s/n La Cañada de San Urbano, 04120 Almería, Spain \\ ${ }^{\mathrm{b}}$ GeologyDepartment of Geosciences and Natural Resource Management, University of Copenhagen, Øster Voldgade 10, 1350 Copenhagen K, Denmark \\ ' International Research Institute for Climate E' Society (IRI), The Earth Institute, Columbia University, Palisades, NY 10964-8000, USA \\ d Departamento de Sistemas Físicos, Químicos y Naturales, Universidad Pablo de Olavide, 41013 Sevilla, Spain \\ e IFAPA, Consejeria de Agricultura, Pesca y Medio Ambiente de Andalucia, Apdo.3092, 14080 Córdoba, Spain \\ ${ }^{\mathrm{f}}$ Instituto de Agricultura Sostenible (IAS), Consejo Superior de Investigaciones Cientificas (CSIC), 14004 Córdoba, Spain
}

\section{A R T I C L E I N F O}

\section{Article history:}

Received 23 August 2012

Received in revised form 10 April 2013

Accepted 7 May 2013

Available online xxxx

\section{Keywords:}

Mediterranean drylands

Surface temperature

Two-source model

Surface energy fluxes

Priestley-Taylor assumption

Parallel and series resistance network

\begin{abstract}
A B S T R A C T
A two-source model (TSM) for surface energy balance, considering explicitly soil and vegetation components, was tested under water stress conditions. The TSM evaluated estimates the sensible heat flux $(H)$ using the surface-air thermal gradient and the latent heat flux $(L E)$ as a residual from the surface energy balance equation. The analysis was performed in a semiarid Mediterranean tussock grassland in southeast Spain, where $H$ is the dominant flux and $L E$ rates are low, challenging conditions under which the TSM has not been validated before. We evaluated two different resistance schemes: series and parallel; as well as the iterative algorithm included in the TSM to disaggregate the soil-surface composite temperature into its separate components. Continuous field measurements of composite soil-vegetation surface temperature $\left(T_{R}\right)$ and bare soil temperature $\left(T_{s}\right)$ from thermal infrared sensors were used for model testing along with canopy temperature estimates $\left(T_{C}^{\prime}\right)$, derived from $T_{R}$ and $T_{s}$.

Comparisons with Eddy covariance and field data showed that the TSM produced reliable estimates of net radiation $(R n)$ and $H$ fluxes, with errors of $\sim 30 \%$ and $\sim 10 \%$, respectively, but not for $L E$, with errors $\sim 90 \%$. Despite of lower errors $(\sim 10 \%)$ in estimating $H$ using parallel resistance, the series scheme was more robust showing slightly higher correlations $\left(r^{2}=0.78-0.80\right.$ vs. $\left.r^{2}=0.75-0.77\right)$ and allowing a better disaggregation of soil and canopy fluxes. Differences between model runs using the iterative algorithm to disaggregate $T_{R}$ and the simplified version that uses separate inputs of $T_{S}$ and $T^{\prime}{ }_{c}$ were minor. This demonstrates the robustness of the iterative procedure to disaggregate a composite soil-vegetation temperature into separate soil and vegetation components in semiarid environments with good prospects for image applications.
\end{abstract}

(c) 2013 Elsevier Inc. All rights reserved.

\section{Introduction}

Land surface temperature is an integrated variable determined by the interaction between the land surface and the atmosphere (Choudhury, 1992), and it is a key factor for partitioning available energy into sensible heat flux $(H)$ and latent heat flux ( $L E)$ (Kustas \& Norman, 1996). Consequently, land surface temperature is one of the remote sensing variables most widely used for surface flux modelling, as shown by the large number of papers published since the 1980s (for review see Glenn et al., 2007; Kalma et al., 2008; Kustas \& Anderson, 2009).

Some difficulties associated with the application of remotely sensed surface temperature for land surface flux modelling have been pointed out. They include angular dependence (Rasmussen et al., 2011), atmospheric and emissivity correction requirements (Dash et al., 2002), and

\footnotetext{
* Corresponding author. Tel.: + 345053123847.

E-mail address: lmorillasgonzalez@yahoo.es (L. Morillas).
}

differences between aerodynamic and radiometric surface temperature (Chehbouni et al., 1997; Norman \& Becker, 1995). These difficulties have contributed to scepticism in the research community about its operational usefulness (Cleugh et al., 2007; Hall et al., 1992). Nonetheless, great advances have been made in application of thermal infrared remote sensing to land surface flux estimation, and today, a wide range of operational remote sensing models relying on the use of surface temperature is available (Kalma et al., 2008; Kustas \& Anderson, 2009).

This paper focuses on physical models based on a direct estimation of the sensible heat flux, which is governed by the bulk resistance equation for heat transfer (Brutsaert, 1982), and relies on the surface-to-air temperature gradient. The latent heat flux can then be estimated as the difference between the available energy minus the sensible heat flux. These models were originally designed from a one-source perspective where the soil-canopy system was represented by an ensemble surface temperature, called the "aerodynamic temperature" $\left(T_{\text {aero }}\right)$, which determines the total sensible heat flux (Kustas \& Anderson, 
2009). The drawback of this perspective is that the aerodynamic temperature cannot be measured by remote sensing. Therefore, in some one-source models where $T_{\text {aero }}$ has been replaced by the radiometric surface temperature $\left(T_{R}\right)$, an extra resistance, called the excess resistance $\left(R_{e x}\right)$, has been included to account for the differences between these two temperatures (see Norman \& Becker, 1995 for clarification of the thermal terminology). Appropriately calibrated, one-source models have shown satisfactory estimates of surface energy fluxes in heterogeneous landscapes (Bastiaanssen et al., 1998; Kustas et al., 1996; Troufleau et al., 1997), however, they show a highly empirical dependency which questions its operational application, particularly in areas where no field flux measurements are available.

To overcome these limitations, one-source models have evolved into a multisource formulation. Following this trend, the Two-Source Model (TSM) for sensible heat flux $(H)$ designed by Norman et al. (1995), provides a more realistic representation of the turbulent and radiation exchanges over partial vegetation canopies than one-source models (Timmermans et al., 2007). The TSM accommodates the difference between $T_{R}$ and $T_{\text {aero }}$ by considering soil $\left(H_{s}\right)$ and canopy $\left(H_{c}\right)$ sensible heat fluxes separately, using the temperature of soil $\left(T_{s}\right)$ and canopy $\left(T_{c}\right)$ respectively. Since remote sensing resolution is often too coarse to distinguish between $T_{s}$ and $T_{c}$, the TSM model includes an algorithm for estimating $T_{S}$ and $T_{c}$ from mono-angle $T_{R}$. This algorithm assumes as a first condition that canopy latent heat flux $\left(L E_{c}\right)$ responds to a potential rate estimated by the Priestley-Taylor equation (Priestley \& Taylor, 1972). From this starting point, the iterative procedure estimates $T_{s}$ and $T_{c}$ and solves the soil and canopy turbulent heat fluxes by applying the surface energy balance equation to canopy and soil separately (see Section 2 for more details). Depending on the coupling assumed between soil and canopy fluxes, the TSM can be applied under two different resistance networks: the parallel approach, which assumes no interaction between sources, and series approach, which allows interaction between soil and canopy (Norman et al., 1995).

Sensitivity analyses of the TSM have shown that it is more robust than one or other two-source temperature models (Zhan et al., 1996), and generally outperforms one-source schemes in extreme climatic conditions (Kustas \& Anderson, 2009). In addition, the TSM allows surface energy fluxes between soil and canopy to be distinguished. This makes possible to obtain separate soil evaporation and canopy transpiration estimates, critical to understanding vegetation processes and water dynamics in drylands (Huxman et al., 2005; Reynolds et al., 2000). Such evidences suggest that the TSM is a good candidate for application to Mediterranean drylands. The effectiveness of the TSM model has been successfully proven in partially covered agricultural areas, including semiarid areas, but mainly under irrigated conditions (Colaizzi et al., 2012b; French et al., 2007; Gonzalez-Dugo et al., 2009; Kustas \& Norman, 1999a; Li et al., 2005). Only a few studies have tested the TSM model under natural semiarid conditions, most of them at the Walnut Gulch (AZ, USA) experimental site (Norman et al., 1995; Timmermans et al., 2007; Zhan et al., 1996), and no experimental analysis of the TSM effectiveness in Mediterranean drylands has been previously presented.

This paper explores the usefulness of the TSM for surface flux estimation in a Mediterranean tussock grassland located in southeast Spain. In these ecosystems, water availability and energy supply conditions do not coincide, resulting in extremely low evapotranspiration rates and dominant $H$ (García et al., 2013; Rana \& Katerji, 2000), which makes for very challenging conditions for running the model. At the same time, two practical aspects of the TSM were analyzed for model application in these specific conditions: the most appropriate arrangement of resistances (parallel or series approach), and the behavior of the iterative procedure included in the model to retrieve canopy and soil temperatures.

Even though parallel resistance network was originally proposed for sparsely vegetated semiarid regions, and series approach for denser vegetation cover (Kustas \& Norman, 1997; Norman et al., 1995), there is no agreement about which approach offers better results in semiarid sparse vegetation. Kustas and Norman (1999a) found better results using the series resistance network in an irrigated cotton crop in central Arizona, whereas Li et al. (2005) found similar results with either parallel or series formulation in corn and soy crops under a wide range of fractional vegetation cover and soil moisture conditions. Due to its greater simplicity, and based on Li et al. (2005), later work has preferably applied the parallel TSM formulation (Sánchez et al., 2008; Timmermans et al., 2007) with good results under natural semiarid ecosystems, but it has never been properly compared with the series approach under these conditions.

With regard to the iterative procedure for separating canopy and soil temperatures and fluxes, some uncertainties have previously been described concerning the best empirical value for the Priestley-Taylor constant $\alpha_{P T}$ (usually $\alpha_{P T}=1.3$ ) (Agam et al., 2010; Kustas \& Norman, 1999a). Colaizzi et al. (2012a) also reported unreliable partitioning between soil and canopy fluxes using the iterative procedure based on Priestley-Taylor in irrigated row crops. Therefore, reevaluation of the effectiveness of this iterative procedure under Mediterranean natural semiarid conditions, where potential evapotranspiration is rarely reached and iteration is strongly forced, seems highly advisable.

These two aspects of the TSM implementation in Mediterranean drylands were evaluated by: i) applying the two possible resistance approaches, series and parallel, to our field site and comparing them, and ii) comparing the results from TSM using a composite soil-vegetation temperature $T_{R}$ and the iterative procedure for flux partitioning, with results using separate $T_{S}$ and $T_{c}$-and hence without iteration-to evaluate uncertainties associated with the iterative procedure included in the TSM formulation.

A dataset of continuous ground measurements during 5-months was used in this assessment. This allowed the effectiveness of the TSM to be evaluated under a wide range of natural micrometeorological and water availability conditions.

\section{Model overview}

We used the TSM proposed by Norman et al. (1995) including the latest improvements proposed by Kustas and Norman (1999a). This model is based on the Surface Energy Balance equation (SEB) which can be formulated for the whole canopy-soil system (Eq. 1) as well as for the canopy layer and the soil layer (designed by $c$ and $s$ subscripts respectively) (Eqs. 2 and 3):

$R n=L E+H+G$

$R n_{c}=H_{c}+L E_{c}$

$R n_{s}=H_{s}+L E_{s}+G$

where $R n$ is net radiation and $G$ is soil heat flux, which includes all the fluxes in $\mathrm{W} \mathrm{m}^{-2}$. In this way, all total surface fluxes can be estimated as the sum of their respective portions for the canopy and soil layers with the exception of the soil heat flux $(G)$ which was originally proposed to be estimated as a constant fraction of $R n_{s}$ (Choudhury, 1987) (Eq. 4).

$G={ }_{c_{G}} R n_{s}$

More detailed methods to estimate $G$ have been recently used to test the TSM (Colaizzi et al., 2012b; Kustas et al., 2012) based on Santanello and Friedl (2003) but showing still considerable uncertainty. Therefore, in the present paper, measured $G$ was used to reduce the effect of $G$ uncertainties over $L E$ estimates, more sensitive to errors due to the low magnitude of $L E$ characterizing Mediterranean drylands (Domingo et al., 2011).

To estimate $R n_{s}$ and $R n_{c}$, the method proposed by Kustas and Norman (1999a) for sparse canopies was used (see detailed formulation 
in the Appendix A). This method replaces the Beer's law-type formulation proposed originally by Norman et al. (1995) and derives net radiation for soil and canopy considering long-wave and short-wave components.

To estimate $H_{c}$ and $H_{s}$ the TSM resistance network may be considered to be either in parallel $\left(T S M_{P}\right)$ or in series $\left(T S M_{S}\right)$. TSM $M_{P}$ assumes that the air temperature above the soil surface is independent of the vegetation temperature, while $T_{S M}$ permits interaction between soil and vegetation heat fluxes, influencing thus the temperature in the air-canopy interface (diagrams of resistances can be found in Fig. 1 of Li et al., 2005).

The $\operatorname{TSM}_{P}$ expression for $H_{c}$ and $H_{s}$ is as follows:

$H_{s}=\rho C_{P} \frac{T_{s}-T_{a}}{r_{A H}+r_{s}}$

$H_{c}=\rho C_{P} \frac{T_{c}-T_{a}}{r_{A H}}$

where $r_{A H}\left(\mathrm{~s} \mathrm{~m}^{-1}\right)$ is the aerodynamic resistance to turbulent heat transport between the canopy source/sink height and $r_{s}\left(\mathrm{~s} \mathrm{~m}^{-1}\right)$ is the resistance to heat flow in the boundary layer immediately above the soil surface. $r_{A H}$ was calculated according to Norman et al. (1995) and $r_{s}$ according to Kustas and Norman (1999a).

For the $T S M_{s}, H_{c}$ and $H_{s}$ are defined by

$H_{s}=\rho C_{P} \frac{T_{s}-T_{a c}}{r_{s}}$

$H_{c}=\rho C_{P} \frac{T_{c}-T_{a c}}{r_{x}}$

where $T_{a c}(\mathrm{~K})$ is the air temperature in the canopy-air space included in Eq. (9):

$H=\rho C_{P} \frac{T_{a c}-T_{a}}{r_{a}}$

where $r_{x}\left(\mathrm{~s} \mathrm{~m}^{-1}\right)$ is the resistance in the boundary layer near the canopy and $r_{a}\left(\mathrm{~s} \mathrm{~m}^{-1}\right)$ is the aerodynamic resistance. $r_{x}$ was calculated according to Norman et al. (1995) and $r_{a}$ was computed according to Kustas and Norman (1999a).

The TSM is based on single-time surface radiometric temperature observations $\left(T_{R}\right)$ which is related to the soil $\left(T_{S}\right)$ and canopy $\left(T_{c}\right)$ radiometric temperatures based on the fractional vegetation cover within the sensor field of view, $f c$, as follows:

$T_{R}=\left[f c T_{c}{ }^{4}+(1-f c) T_{s}^{4}\right]^{1 / 4}$

where all temperatures are in $\mathrm{K}$.

In the TSM $T_{c}$ and $T_{S}$ are estimated from $T_{R}$ by iteration for Eqs. (5)-(6) $\left(T S M_{P}\right)$ or (7)-(8) $\left(T S M_{S}\right)$. As a starting point for determining the divergence between soil and canopy fluxes, the iteration procedure uses the Priestley-Taylor equation (Priestley \& Taylor 1972) (Eq. (11)) to estimate an initial $L E_{c}$.

$L E_{c}=\alpha_{P T} f_{G} \frac{\Delta}{\Delta+\gamma} R n_{c}$

where $\alpha_{P T}$ is the Priestley-Taylor parameter $(\approx 1.3), f_{G}$ is the fraction of leaf area index ( $L A I)$ that is green or actively transpiring, $\Delta$ is the slope of the saturation vapor pressure-temperature curve at $T_{c}\left(\mathrm{kPa} \mathrm{K}^{-1}\right)$ and $\gamma$ is the psychrometric constant $\left(\mathrm{kPa} \mathrm{K}^{-1}\right)$.

Once the initial $L E_{c}$ is obtained from Eq. 11 , an initial $H_{c}$ is derived using the estimated $R n_{c}$ from Eq. (2) and $T_{c}$ is obtained from inversion of Eqs. (6) $\left(T S M_{P}\right)$ or (8) $\left(T S M_{S}\right) . T_{S}$ is estimated from this initial $T_{c}$ by Eq. (10) and $H_{\mathrm{s}}$ by Eqs. (5) or (7) (depending on the resistance approach). Finally an initial $L E_{s}$ can be obtained by Eq. (3) using estimated $R n_{s}$ and $G$. This equation system is the basis of the iterative procedure. If the estimated $L E_{s}$ is above zero, iteration stops, as a reliable solution has been reached. On the contrary, when the estimated $L E_{s}$ is below zero, an unrealistic situation under daytime conditions is assumed since condensation in the soil is very unlikely to occur. This is considered a sign of water stress, and consequently $L E_{s}$ is set to zero and $L E_{c}$ falls from its initial potential rate. Therefore, the initial $L E_{c}$ is overridden and $\alpha_{P T}$ is iteratively reduced until the solutions for $T_{C}$ and $T_{s}$ agree with measured $T_{R}$ through Eq. (10) and realistic latent heat fluxes are found for both canopy and soil $\left(L E_{s} \geq 0\right.$ and $L E_{c} \geq 0$ for daytime) (Kustas et al., 2012; Norman et al., 1995). Sometimes, even when $L E_{s}$ and $L E_{c}$ are set at zero, the resulting $H_{s}$ (residually estimated from Eq. 3) exceeds the energy available to the soil $\left(H_{s}>R n_{s}-G\right)$. In such situations, the iterative procedure, originally designed to use estimated $G$ from Eq. (4), considers unreliable the constant value of $c_{g}$ used in Eq. (4) and finds a "residual solution" by inverting $G$ from Eq. (3) to satisfy both the soil and canopy surface energy balances (Norman et al., 1995). As in our study, measured values of $G$ were used for model running, those cases for which iteration was not able to reach the soil energy closure when $L E_{s}=0$ and $L E_{c}=0$ using measured $G$, were considered as an iteration failure and were not included in the accuracy analyses.

Iteration is not required for the TSM when $T_{s}$ and $T_{c}$ are known a priori. In that case $H_{c}$ and $H_{s}$ can be estimated directly using Eqs. (5)-(8) and the latent heat fluxes computed as a residual of each energy balance layer (Eqs. (2) and (3)). This model is hereinafter referred to as TSM without iteration, to differentiate it from the TSM with iteration based on $T_{R}$ measurements.

\section{Material and methods}

\subsection{Study site and field measurements}

The Balsa Blanca field site is located $6.3 \mathrm{~km}$ from the coast $\left(36^{\circ} 56^{\prime}\right.$ 24.17"N; $2^{\circ} 1^{\prime} 59.55^{\prime \prime} \mathrm{W}$; elevation $196 \mathrm{~m}$ a.m.s.l.) in Cabo de Gata National Park. Mean annual rainfall is $375 \mathrm{~mm}$ and mean annual temperature is $18.1{ }^{\circ} \mathrm{C}$ (García et al., 2013) The site is a tussock grassland, where the predominant specie is Stipa tenacissima L. (57.2\%), a perennial grass, with other less abundant shrub species, such as Thymus hyemalis Lange (1.7\%), Chamaerops humilis L. (1.6\%), Brachypodium retusum (Pers.) P. Beauv (1.4\%), Ulex parviflorus Pourr (0.5\%) and Phlomis purpurea $\mathrm{L}$. $(0.2 \%)$. Because the vegetation is perennial, measured values of cover fraction ( $f c=0.6)$ and canopy height $\left(h_{c}=0.7 \mathrm{~m}\right)$ can be considered constant during the study period. The model was tested from January 15th, (day of year-DOY 15) to June 9th (DOY 160) 2011. This period covers the wide range of soil water availability and phenological conditions shown in Fig. 1. During the study period, the volumetric soil moisture content, measured at a depth of $4 \mathrm{~cm}$ in a bare soil area with a water content reflectometer (model CS616, Campbell scientific INC., USA), ranged from a minimum of 7 to a maximum of $24 \%$, which covered the range of annual variation. The evaporative fraction, defined as the ratio of latent heat flux $(L E)$ to available energy $(R n-G)$, ranged from 0.07 to 0.49 (at midday) (notice that the evaporative fraction never exceeded 0.5 ) and LAI from MODIS ranged from 0.3 to 0.7 .

Continuous $T_{R}$ and $T_{S}$ measurements were acquired using Apogee IRTS-P broadband thermal infrared thermometers (Campbell Scientific Inc., USA). This broadband radiometer has a full wavelength range of 6 to $14 \mu \mathrm{m}$. Two IRT sensors were installed at heights of $3.50 \mathrm{~m}$ and $0.65 \mathrm{~m}$, measuring two target surfaces at nadir, respectively: a) composite soil-vegetation surface and b) a pure bare soil surface (Fig. 2). The half field of view of $28^{\circ}$ resulted in a soil and vegetation mixture $\left(T_{R}\right)$ sampling area $3.70 \mathrm{~m}$ in diameter and a bare soil $\left(T_{s}\right)$ sampling area $0.69 \mathrm{~m}$ in diameter. Incoming short-wave radiation was also measured at a height of $3.50 \mathrm{~m}$ using an LP02 Pyranometer (Campbell Scientific Inc., USA). Temperatures and radiance were measured every 

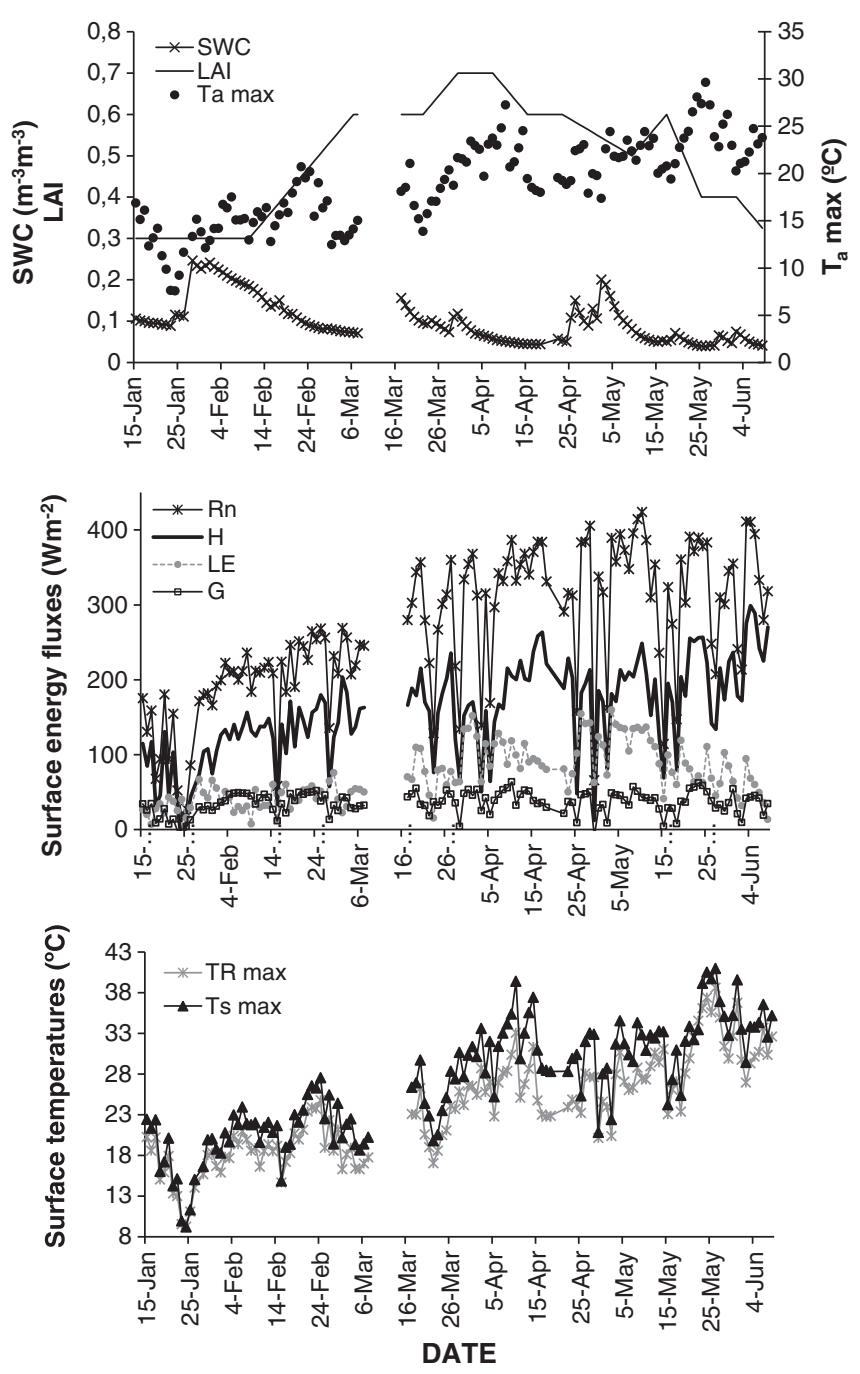

Fig. 1. Variation in leaf area index (LAI) from MODIS over time, soil water content at midday (SWC) and daily maximum air temperatures ( $T_{a} \max$ ) (top), variation in observed surface fluxes: net radiation $(\mathrm{Rn})$, sensible heat flux $(H)$, latent heat flux $(L E)$ and soil heat flux $(\mathrm{G})$ (daytime period averages shown) (middle panel) and daily maximum composite soil-vegetation surface $\left(T_{R}\right)$ and bare soil $\left(T_{S}\right)$ temperatures (bottom panel) during the study period.

minute and stored as 15-min averages on a Campbell CR1000 datalogger (Campbell Scientific Inc., USA).

Temperature and radiance measurements were acquired within the footprint of Eddy Covariance (EC) tower located at this field site (see Section 3.4). The EC system for $H$ and $L E$ measurement included a three-dimensional sonic anemometer CSAT3 (Campbell Scientific Ltd, USA) measuring wind speed and direction, and a LI-COR open-path infrared gas analyzer (Li7500, Campbell Scientific Ltd, USA) measuring water vapor and $\mathrm{CO}_{2}$ concentrations. Both $\mathrm{EC}$ system components, located $3.5 \mathrm{~m}$ high and connected to the Campbell CR3000 datalogger (Campbell Scientific Ltd, USA), measured at $10 \mathrm{~Hz}$, and the datalogger calculated and stored means, variances and covariances every $15 \mathrm{~min}$. $L E$ measurements were corrected for air density fluctuations from heat and water vapor flux as proposed by Webb et al. (1980), and for the rotation of the coordinate system (Kowalski et al., 1997; McMillen, 1988). Air temperature $\left(T_{a}\right)$ and humidity $(R H)$ were also measured every minute using a thermo-hygrometer (HMP45C, Campbell Scientific Ltd.) located at a height of $2.5 \mathrm{~m}$ on the EC tower. Net radiation $(R n)$ was measured every minute at a height of $1.90 \mathrm{~m}$ over a mixture of canopy and soil surface using a net radiometer (NR-Lite; Kipp \& Zonen, Campbell Scientific Ltd, USA). $R n, R H$ and $T_{a} 15$-min-averages were recorded by the same Campbell CR3000 datalogger used for the EC system data.
In addition, the soil heat flux $(G)$ was calculated by the combined method (Fuchs, 1986; Massman, 1992) by adding the average flux measured by a soil heat flux plate at a fixed depth (in this case $0.08 \mathrm{~m}$ ) (HFT-3; REBS, Seattle,Wa, USA) to the energy stored in the soil layer above the heat flux plate measured using two thermocouples (TCAV, Campbell Scientific Ltd.) buried at $0.02 \mathrm{~m}$ and $0.06 \mathrm{~m}$ over the flux plates. Two pairs of soil heat flux plates and their corresponding thermocouples were installed in bare soil and under plant positions for computing $G_{b s}$ and $G_{u p}$, respectively. Soil temperatures and fluxes were measured every minute and 15-min averages were recorded by a CR10X datalogger (Campbell Scientific Inc., USA). Representative data for $G$ at the experimental site was computed as $G=f c G_{u p}+(1-f c)$ $G_{b s}$, where $f c$ is the vegetation cover fraction at the site.

\subsection{Satellite and airborne campaign data}

LAI and fraction of Photosynthetic Active Radiation $\left(f_{\text {PAR }}\right)$ from the MODIS (Moderate Resolution Imaging Spectroradiometer) sensor were acquired as TSM model inputs. The $f_{P A R}$ product was used to estimate $f_{g}$, included in Eq. (11), as the ratio between intercepted and absorbed Photosynthetic Active Radiation $f_{\text {IPAR }} / f_{A P A R}$ (Fisher et al., 2008). MODIS data from Terra, MOD15A (Collection 5), and from the Aqua satellites, MYD15A2, were used. The mean of Terra and Aqua 8-day composites (1-km pixel) for each product was linearly interpolated between observations for daily estimates.

To assess the variability of surface temperature $\left(T_{R}\right)$ within the footprint of the EC tower four Very High Resolution (VHR) images of $0.4 \mathrm{~m}$ pixel acquired from an unmanned airborne campaign over the site in May-18th-2009 at 7.00 h, 9:10 h, 11:38 h and 14:10 h (solar time) were used. The Unmanned Aerial Vehicle (UAV) platform was a 2-m wingspan fixed-wing platform with up to 1-hour endurance at $5.8 \mathrm{~kg}$ take-off weight (TOW) and $63 \mathrm{~km} / \mathrm{h}$ ground speed (mX-SIGHT, UAV Services and Systems, Germany) operated by the Laboratory for Research Methods in Quantitative Remote Sensing (QuantaLab, IAS-CSIC, Spain) and adapted to carry a payload consisting on a thermal camera (Berni et al., 2009; Zarco-Tejada et al., 2012). The UAV was controlled by an autopilot (AP04, UAV Navigation, Madrid, Spain) to follow a flight plan (Berni et al., 2009).

The Miricle 307 thermal camera (Thermoteknix Systems Ltd, Cambridge, UK) was flown over the study sites with a $14.25 \mathrm{~mm}$ f1.3 lens, connected to a computer onboard the unmanned vehicle. The image sensor was a Focal Plane Array (FPA) based on uncooled microbolometers with a resolution of $640 \times 480$ pixels and a spectral response in the range of $8-12 \mu \mathrm{m}$, yielding a $25 \mu \mathrm{m}$ pixel size. The camera delivered uncalibrated 14-bit digital raw images. Radiometric calibration was conducted in the laboratory using blackbodies under varying target and ambient temperatures to develop radiometric calibration algorithms. Atmospheric correction methods were applied to the thermal imagery based on the MODTRAN radiative transfer model to obtain surface temperature. Local atmospheric conditions were determined by air temperature, relative humidity and barometric pressure measurements at the time of flight using a portable weather station (Model WXT510, Vaisala, Finland). Atmospheric correction methods conducted with single-band thermal cameras were shown to provide successful estimation of vegetation surface temperature (Berni et al., 2009). Bouguet's image calibration procedure was applied to all imagery acquired (Berni et al., 2009) and photogrammetric techniques were used to register the frame-based imagery to map coordinates. Three of the images were co-registered a posteriori to the image acquired at $7.00 \mathrm{~h}$ achieving a geolocation error of 4 pixels.

To assess the variability of LAI at the study site we used an ASTER (Advanced Spaceborne Thermal Emission and Reflection Radiometer) from May-6th-2003 at 11.00 UTC. ASTER, on board the Terra platform along with MODIS scans a $60 \mathrm{~km}$ swath on the ground every 16 days with a swath angle of $\pm 2.4^{\circ}$. The sensor has nine reflective bands and five bands in the thermal infrared (TIR) region. To estimate the 

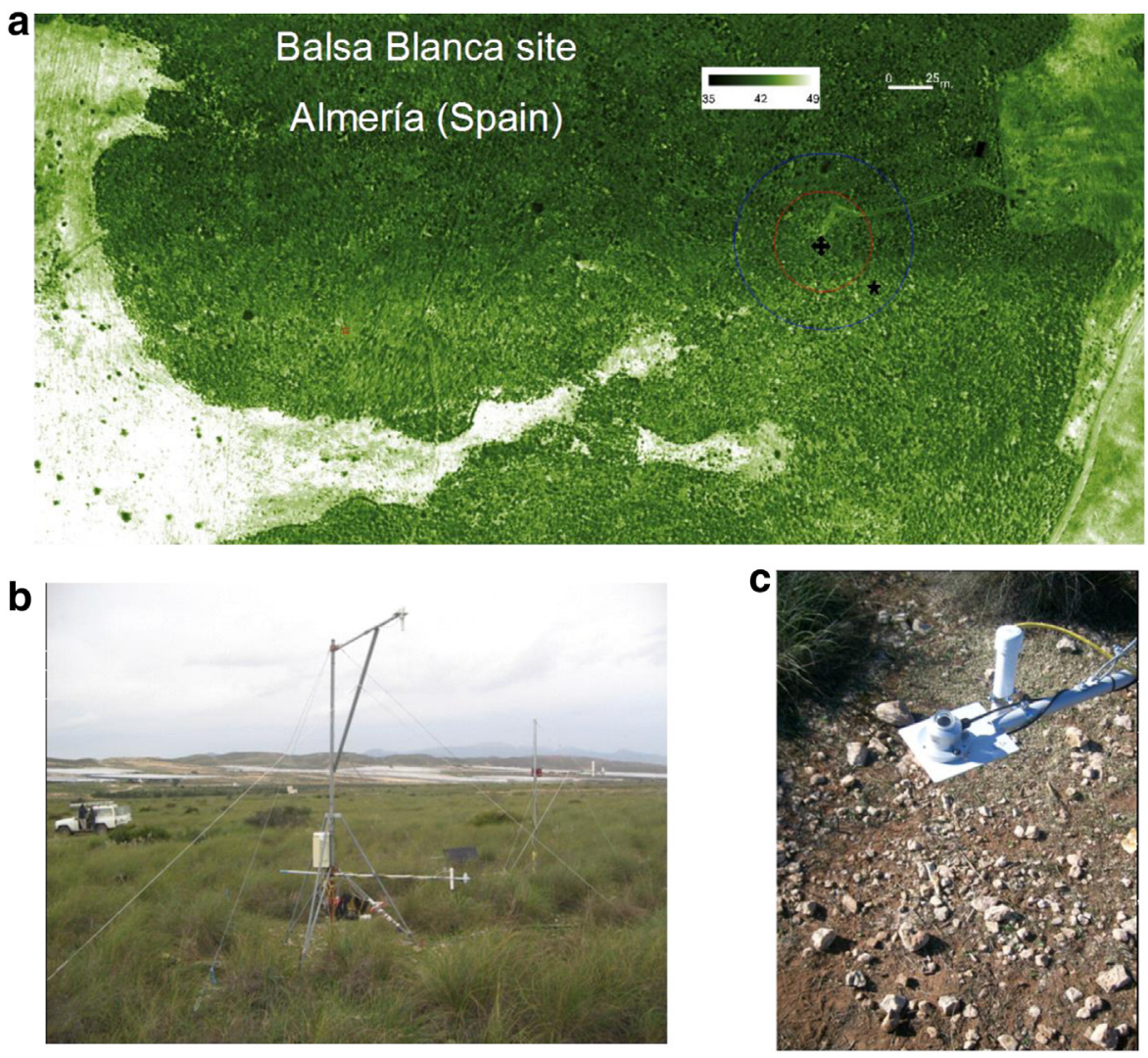

Fig. 2. (a) Thermal image from an Unmanned Aerial Vehicle (UAV) of $40 \mathrm{~cm}$ spatial resolution from May-18th-2009 at $11: 30 \mathrm{~h}$ over the study site of Balsa Blanca (36 $56^{\prime} 24.17^{\prime \prime} \mathrm{N}$ $\left.2^{\circ} 1^{\prime} 59.55^{\prime \prime} \mathrm{W}\right)$. A cross shows the location of the Eddy Covariance tower, a star the location of the Apogee IRT-P sensors and the circles represent the mean footprint for unstable (red) and stable (blue) conditions. (b) Panoramic view of the study site with the Apogee IRT-P sensors set up. (c) Detail of Apogee IRT-P sensor measuring over the bare soil sampling area. (For interpretation of the references to color in this figure legend, the reader is referred to the web version of this article.)

NDVI (15 m pixel) we used the surface reflectance product (2AST07; HDFEOS version 2.8), with a spatial resolution of $15 \mathrm{~m}$ (VNIR) and $30 \mathrm{~m}$ (SWIR) and an absolute accuracy of $4 \%$ of reflectance (Abrams \& Hook, 2002).

\subsection{Pre-processing of radiometric measurements}

The Apogee IRT-P sensors, with reported accurate of $\pm 0.3{ }^{\circ} \mathrm{C}$ within a range of -10 to $55{ }^{\circ} \mathrm{C}$, were programmed to correct for the effect of the internal sensor temperature and the thermal mass (Bugbee et al., 1996). To ensure that the reported accuracy of IRT sensors is maintained under our extreme field conditions, they were recalibrated in the laboratory with a blackbody calibration source (Raytek BB4000) before their installation in the field. The two IRT sensors, labelled as IRT $\mathrm{Ioil}_{\text {ail }}$ and IRT $\mathrm{I}_{\text {composite, }}$ according to their position in the experimental field set up, were tested in a growth chamber under different combinations of black body temperatures $\left(T_{B B}\right)$, ranging from 20 to $70{ }^{\circ} \mathrm{C}$, and air temperatures $\left(T_{a}\right)$, ranging from 5 to $30^{\circ} \mathrm{C}$. Temperatures were measured every 15 seconds and 5-minaverages were recorded in a Campbell CR1000 datalogger. Mean measurement errors exceeded the reported accuracy (see Table 1) when target temperatures were over $50{ }^{\circ} \mathrm{C}$. Given that surface temperatures higher than $50{ }^{\circ} \mathrm{C}$ have been described under semiarid conditions (Chehbouni et al., 2001), we corrected the IRT measurements following the regression line between the Apogee IRT and the blackbody temperatures over the whole range of temperatures tested in the laboratory calibration (see calibration line in Table 1).

In addition to this calibration, emissivity and atmospheric effects were also accounted for. The radiance reaching the IRT radiometers, $R_{B}$, is the result of two main contributions: a) the radiance emitted by the surface because of its temperature, and $b$ ) the portion of downwelling long-wave sky radiation reflected by the surface (Norman \& Becker, 1995):

$R_{B}=\varepsilon R_{R}+(1-\varepsilon) L$

where $\varepsilon$ is surface emissivity, $R_{R}$ is the black body surface spectral radiance according to the surface radiometric temperature $\left(T_{R}\right)$, and $L$ is the hemispheric downwelling long-wave radiance from the sky divided by $\pi$.

The IRT radiometers provide measurements as brightness temperatures $\left(T_{B}\right)$ related to brightness radiance $\left(R_{B}\right)$, assuming emissivity equal to 1 . Therefore, in order to estimate $R_{R}$, first $R_{B}$ was estimated from the IRT measurements by applying the Stefan-Boltzman equation, and second $R_{R}$ was derived from Eq. (12) for each IRT sensor using known emissivity and downwelling long-wave radiance. Once the radiometric radiances, $R_{R}$, from the IRT soil $_{\text {and }}$ IRT $\mathrm{T}_{\text {composite }}$ sensors had been found, the $T_{\mathrm{S}}$ and $T_{R}$ radiometric, or "corrected", temperatures were found using the Stefan-Boltzman equation.

Table 1

Results of laboratory calibration of the Apogee IRT-P sensors. Mean absolute error (MAE) in ${ }^{\circ} \mathrm{C}$ of each sensor in different scenarios: for all the temperature combinations tested (MAE), for the range of temperatures reported by the manufacturer ${ }^{\mathrm{a}}\left(\mathrm{MAE}_{\text {range }}\right)$ and for the temperatures tested out of the manufacturer range $\left(\mathrm{MAE}_{\text {out of range }}\right)$. Air temperature $\left(T_{a}\right)$ and black body temperature $\left(T_{B B}\right)$ ranges considered for each scenario are expressed in ${ }^{\circ} \mathrm{C}$. The final calibration line applied to each sensor is also shown.

\begin{tabular}{lllll}
\hline General stats & $T_{a}$ range & $T_{B B}$ range & IRT $_{\text {soil }}$ & IRT $_{\text {composite }}$ \\
\hline MAE & $5-30$ & $20-70$ & $\mathbf{0 . 4 2}$ & $\mathbf{0 . 4 2}$ \\
MAE $_{\text {range }}$ & $5-30$ & $20-50$ & 0.26 & 0.31 \\
MAE $_{\text {out range }}$ & $5-30$ & $60-70$ & $\mathbf{0 . 7 2}$ & $\mathbf{0 . 6 2}$ \\
Empirical calibration line & & & $y=1.01 x-0.03$ & $y=1.00 x-0.06$ \\
\hline
\end{tabular}

a Reported accuracy: $\pm 0.3^{\circ} \mathrm{C}$ from -10 to $55^{\circ} \mathrm{C}$. 
For $T_{s}$ emissivity corrections we considered soil emissivity, $\varepsilon_{s}=0.95$, associated with bare soils in open and closed shrublands (Trigo et al., 2008). Although some studies have shown that $\varepsilon_{\mathrm{s}}$ can vary with soil water content fluctuation (Mira et al., 2007), a constant value was used because the effects of that variation are in the same range as the Apogee IRT sensor error (Sánchez et al., 2009). For $T_{R}$ emissivity corrections, the composite emissivity $\left(\varepsilon_{R}\right)$, which depends on the vegetation fraction cover $(f c=0.6)$, was estimated as a linear combination of both soil and canopy emissivities, $\varepsilon_{\mathrm{s}}$ and $\varepsilon_{\mathrm{c}}$, respectively (Sobrino et al., 2001) (Eq. 13). For $\varepsilon_{c}$ we used $\varepsilon_{c}=0.99$, measured in the field at a similar site for $S$. tenacissima (Villagarcía, 2000).

$\varepsilon_{R}=f c \varepsilon_{c}+(1-f c) \varepsilon_{s}$

The downwelling long-wave radiance $L$ was computed by means of the Stefan-Boltzmann equation using air temperature and atmospheric emissivity. Air temperature and vapor pressure were used for estimating atmospheric emissivity following Brutsaert (1982).

Once $T_{R}$ and $T_{s}$ were found, $T_{c}$ was estimated using Eq. (10). The estimated $T_{c}$ is referred to below as derived $T^{\prime}{ }_{c}$.

\subsection{Analysis of spatial heterogeneity}

Water-limited ecosystems are more vulnerable to a mismatch between tower flux and land surface measurements due to their heterogeneous vegetation composition (Vivoni et al., 2010). If the spatial heterogeneity is high, non-linear aggregation of state variables such as $T_{R}$ and vegetation cover might increase the differences between EC data and model outputs (Ershadi et al., 2013). In our study, model inputs from sensors with footprints different than that of the EC systems were used. As footprints can differed in up to three orders of magnitude is critical to perform an a priori assessment of the spatial variability of the site before running the TSM.

The aim in this Section was twofold: i) to characterize the spatial heterogeneity of the site for vegetation cover and surface temperature. ii) Assess if the composite soil-vegetation surface temperature $\left(T_{R}\right)$ and LAI used as model inputs are representative of effective or the spatially-averaged variables within the footprint of the EC tower.

First, the EC footprint area was characterized using analyses from Were et al. (2010). They applied the Flux Source Area Model (FSAM) of Schmid $(1994,1997)$ at the site that calculates the dimensions of the source area of a given sensor as a function of sensor height, atmospheric stability and wind speed fluctuations. Were et al. (2010) considered the dimensions of the source area responsible for $50 \%$ of the total source weight calculated with FSAM. The footprints of the EC tower for unstable and stable conditions, representing $96.4 \%$ and $0.4 \%$ of the total observations respectively, were defined as a circle of $28.8 \mathrm{~m}$ radius for unstable conditions and $51.1 \mathrm{~m}$ radius for stable conditions (Were et al., 2010) (Fig. 2a).

Then, statistics for $T_{R}$ derived from the UAV images (mean, standard deviation and coefficient of variation, CV) were extracted for four different sites: Apogees footprint site (hereinafter Apogee-site) considered representative of the model input footprint, eddy covariance tower site (hereinafter EC-tower), and two EC footprints (hereinafter EC-footprint stable and EC-footprint unstable). The Apogee-site and the EC-tower regions were defined based on the error from image co-registration $(1.6 \mathrm{~m})$. The pixels $(0.4 \mathrm{~m})$ included a mixture of soil and vegetation, and also some pixels of pure vegetation and bare soil due to the high spatial resolution. Similarly, statistics for NDVI from the ASTER image were extracted for three regions: EC-footprint stable, EC-footprint unstable and MODIS-1 km pixel (same as footprint of model input). Significant differences between mean values from the different regions were assessed using t-tests as NDVI and $T_{R}$ were normally distributed. NDVI was used instead of LAI as no LAI imagery was available at high resolutions. However, NDVI is linearly related with LAI within the range of values found at the study site (LAI $<2 \mathrm{~m}$ ) (Gamon et al., 1995).

\subsection{Model validation}

Model outputs were evaluated by comparing them with the $H$ and $L E$ fluxes derived from the EC system. The slope of the linear regression between the available energy $(R n-G)$ and the sum of the surface fluxes $(H+L E)$ measured every 15 -min by the EC tower was 0.8 , which indicates an average imbalance of about $20 \%$, on the same order as reported by Wilson et al. (2002). However, for model evaluation, the conservation of energy equation must be satisfied (Twine et al., 2000), especially in residual models. Therefore, the residual-LE closure method (Twine et al., 2000) was implemented. This method assumes that most of the EC imbalance is caused by inaccuracies in $L E$, and solves for $L E$ as the residual of the energy balance equation (assuming $H$ is measured accurately). Our choice is based on previous work suggesting that this method would be the most appropriate for validating SEB-based models using EC data (Alfieri et al., 2012; Li et al., 2005), and on studies showing that underestimation of $L E$ by EC is greater than for $H$ (Wang \& Dickinson, 2012).

For model evaluation, our dataset of continuous measurements during the study period was reduced to those 15-min daytime observations with observed $R n$ and $L E$ above zero (not daytime condensation), and model $R n_{s}$ and $R n_{c}$ above zero (minimum energy supply), in order to evaluate the TSM under the conditions it was originally designed for. These criteria left a total of 2991 cases.

\section{Results}

\subsection{Analyses of spatial heterogeneity}

The heterogeneity of the footprint for $T_{R}$ was found to be similar for unstable and stable conditions with standard deviation increasing towards the warmer afternoon hours when the $H$ flux increases as well (Table 2).

The $T_{R}$ representative of the model footprint (Apogee-site) was not significantly different (Fig. 3) from the area-averaged $T_{R}$ over the footprint area under either stable or unstable conditions after midday. However, before noon the area-averaged $T_{R}$ within the footprint area was $\sim 0.8{ }^{\circ} \mathrm{C}$ lower than $T_{R}$ at the Apogee site. This could have a small impact on modeled fluxes, producing $H$ overestimates (Timmermans et al., 2007). Additionally, despite of the fact that the location of the IRT at the Apogee-site is distant from the tower EC-site, $T_{R}$ from both sites are not significantly different at any time of the day.

The area-averaged NDVI within the footprint of the EC tower under unstable conditions, dominant at the site, was not significantly different from that within the MODIS $1 \mathrm{~km}$ pixel (see Table 3) although its $\mathrm{CV}$ was three times greater. However, there is a great deal of published evidence showing that the relationship between surface reflectance is linear across the range of spatial scales of most sensors and atmospheric conditions (Moran et al., 1997). This suggests that using the NDVI from MODIS at $1 \mathrm{~km}$ pixel is equivalent to using the area-averaged NDVI value within the footprint.

\subsection{Series vs. parallel original TSM version}

No significant differences were found between $T S M_{P}$ and $T S M_{S}$ outputs using the TSM in our semiarid site (Fig. 4). Statistics comparing model outputs with EC derived fluxes shown in Table 4, have lower errors with the parallel approach, but explained variance is slightly higher with the series approach.

$T S M_{P}$ and $T S M_{S}$ were equally successful in estimating $R n$ with slopes close to 1 and $r^{2}=0.93$ for all approaches (Fig. $4 \mathrm{a}$ and d), and low Mean Absolute Percentage Errors (MAPE) of 12-13\% (Table 4). However, a tendency to overestimate is observed (Fig. $5 \mathrm{~A}$ and $\mathrm{D}$ ). 
Table 2

Spatial heterogeneity of composite soil-vegetation surface temperature $\left(T_{R}\right)$ within the foot print area for stable and unstable conditions of the Eddy Covariance tower derived from four UAV scenes of $0.4 \mathrm{~m}$ pixel. Mean is the spatially-averaged $T_{R}$ in the area, Std is the standard deviation, $\mathrm{n}$ the number of pixels in the area, and CV the coefficient of variation (\%).

\begin{tabular}{lllllll}
\hline Footprint area & Area $\left(\mathrm{m}^{2}\right)$ & Hour (solar) & Mean & Std & $\mathrm{n}$ & $\mathrm{CV}(\%)$ \\
\hline Footprint stable & 8203.42 & 7.00 & 28.17 & 1.10 & 60,762 & 3.90 \\
& & $9: 10$ & 37.49 & 1.32 & 60,762 & 3.52 \\
& & $11: 38$ & 41.81 & 1.66 & 60,762 & 3.97 \\
Footprint unstable & 2605.78 & $14: 10$ & 40.75 & 1.82 & 60,762 & 4.47 \\
& & 9.00 & 28.20 & 1.11 & 15,852 & 3.94 \\
& & $11: 38$ & 47.47 & 1.11 & 15,852 & 2.96 \\
& & $14: 10$ & 40.59 & 1.51 & 15,852 & 3.61 \\
& & & & & 15,852 & 3.94 \\
\hline
\end{tabular}

Differences in parallel and series model versions were more significant for $H$ than $R n$ (Fig. 4b and e). Both resistance networks showed a better capacity for estimating low $H$ than high $H$ values, with similar accuracy when $H$ was low. At high values of $H$, the $T S M_{S}$ showed a clear tendency to underestimate, whereas $\operatorname{TSM}_{P}$ behavior was more irregular especially using the TSM with iteration as it can be perceived in Fig. 4b. As a result, mean average errors for $H$ were slightly lower with the parallel approach, with MAE values of 51-48 $\mathrm{W} \mathrm{m}^{-2}$ (25$23 \%$ of MAPE) using the TSM with or without iteration respectively than with the series which showed MAE values of $69-71 \mathrm{~W} \mathrm{~m}^{-2}$ (33-34\% of MAPE) respectively. However slightly better correlation $\left(\mathrm{r}^{2}=0.78-080\right.$ vs. $\left.\mathrm{r}^{2}=0.75-78\right)$ and lower scatter (Fig. $4 \mathrm{~b}$ and e) using the series approach was found.

Under the semiarid conditions studied, the TSM showed large relative errors in the latent heat flux, $L E$, with MAE values of 84 $115 \mathrm{~W} \mathrm{~m}^{-2}$ and MAPE in the order of 73-99\% (Table 4). The lower errors were found using the $\operatorname{TSM}_{P}(73-74 \%)$. Linear regressions between modelled and observed $L E$ showed large scatter (Fig. $4 \mathrm{c}$ and f), with $\mathrm{r}^{2}$ below 0.40 for all approaches and despite of $L E$ was mostly overestimated, slope values were close to one (Table 4), denoting greater importance of non-systematic rather than systematic errors.

$T S M_{P}$ and $T S M_{S}$ tackle the partitioning of the turbulent fluxes between soil and canopy in a different way. Although no measurements of soil and canopy fluxes were available for a proper evaluation of this partitioning by $T S M_{P}$ and $T S M_{S}$, the comparison of measured and estimated $T_{s}$ (Fig. 5) showed a general tendency to overestimate $T_{s}$, especially at high temperatures. This tendency, denoting that the TSM would be overestimating $H_{s}$ flux, was more pronounced with the $\operatorname{TSM}_{P}\left(\operatorname{RMSE}=3.37^{\circ} \mathrm{C}\right)$ than with the $T S M_{S}\left(\operatorname{RMSE}=1.67{ }^{\circ} \mathrm{C}\right)$.

\subsection{Evaluating the iteration procedure included in the original TSM}

No significant changes in the scatterplots were found between the TSM with iteration (Fig. 4a-c) and the TSM without iteration (Fig. 4d-f), and statistics were similar (Table 4).

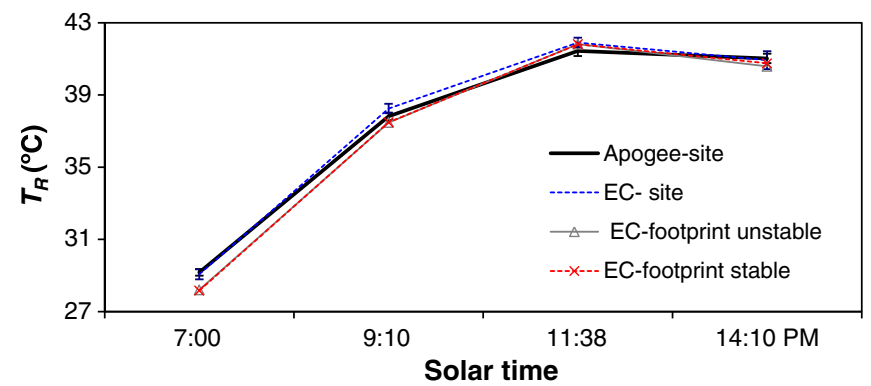

Fig. 3. Comparison of spatially-averaged $T_{R}$ at the IRT Apogee site (Apogee-site), at the Eddy Covariance site (EC-site), and within the footprint regions defined for stable and unstable conditions (EC-footprint stable and EC-footprint unstable respectively). $T_{R}$ were derived from Very High Resolution images from airborne flights at four different times on May-18th -2009 . Error bars represent the confidence interval for significant differences $(\mathrm{p}<0.05)$.
Table 3

Spatial heterogeneity of NDVI within the footprint (stable and unstable conditions) of the Eddy Covariance tower using and the MODIS $1 \mathrm{~km}$ pixel region derived from ASTER (15 $\mathrm{m}$ pixel). Mean is the spatially-averaged NDVI in the area, Std is the standard deviation and CV the coefficient of variation (\%) Significant differences between means at $\mathrm{p}<0.05$ were indicated by different letters.

\begin{tabular}{lrlllrll}
\hline & Area $\left(\mathrm{m}^{2}\right)$ & Mean & Std & $\mathrm{n}$ & $\mathrm{CV}(\%)$ & $\begin{array}{l}\text { Significant } \\
\text { differences }\end{array}$ \\
\hline Footprint stable & 8203.42 & 0.36 & 0.012 & 36 & 3.4 & $\mathrm{a}$ \\
Footprint unstable & 2605.78 & 0.36 & 0.013 & 16 & 3.7 & ab \\
MODIS-1 km pixel & $1,000,000$ & 0.37 & 0.049 & 4434 & 13.2 & $\mathrm{~b}$ \\
\hline
\end{tabular}

Nonetheless, some minor differences in $H$ estimates depending on the model version (with or without iteration) are detected (Fig. 4b and e). These differences were more obvious with the $T S M_{P}$ approach, which increased in bias when $T_{s}$ and $T^{\prime}{ }_{c}$ were used (slope $=0.66 \mathrm{vs}$. slope $=$ $0.72)$ despite of a slight increase of explained variance $\left(r^{2}=0.77 \mathrm{vs}\right.$. $r^{2}=0.75$ ) and decrease of percentage errors (MAPE $=23 \%$ vs. MAPE $=25 \%$ ) compared to the $T S M_{P}$ using iteration. The $T S M_{S}$ presented a very similar behavior using iteration or not, showing the same tendency to underestimate high values of $H$ as well as similar correlations $\left(\mathrm{r}^{2}=\right.$ 0.80 vs. $r^{2}=0.78$ ), slopes ( 0.60 and 0.61 respectively) and overall errors $(\mathrm{MAPE}=34 \%$ and MAPE $=33 \%$ ). These differences on estimation of $H$ using $T_{s}$ and $T^{\prime}{ }_{c}$ did not significantly affected estimates of $L E$. The scatter plots continued to show wide dispersion for both $T_{S M}$ and $T S M_{S}$ (Fig. 4c and f) and only the slopes were reduced from 0.90 to 0.86 , using $T S M_{P}$, and from 0.94 to 0.90 , using $T S M_{S}$, when iteration was not used (see Table 4).

In view of these results (Fig. 4 and Table 4), no strong differences between TSM performance using $T_{S}$ and $T^{\prime}{ }_{c}$ or $T_{R}$ and iteration can be confirmed under natural semiarid conditions. Nonetheless, it is important to consider that the iterative procedure failed in a certain number of cases, not included or discussed in previous analyses. Iteration was not able to achieve energy closure for soil layer using measured $G$ values for those failed cases (See Section 2). These iteration failures were more common using $T S M_{P}, \mathrm{~N}=668$, than $T S M_{S}, \mathrm{~N}=292$. In those cases when iteration failed, the TSM worked properly using observed $T_{s}$ and $T^{\prime}{ }^{\prime}$. In Fig. 6, predicted fluxes from the TSM with iteration and without iteration can be compared for only such cases. When the iteration procedure failed both in series and in parallel, $T S M_{P}$ and $T S M_{S}$, iteration clearly overestimated $H$ (predicted $L E$ was always zero). However, without iteration, $H$ was estimated better and was in good agreement, close to the 1:1 line. The iteration failed when using $T_{S M}$ mostly with low energy supply $\left(R n<300 \mathrm{~W} \mathrm{~m}^{-2}\right)$, whereas $\operatorname{TSM}_{P}$ iteration failed under a wider range of energy supply conditions ( $R n$ between 0 and $600 \mathrm{~W} \mathrm{~m}^{-2}$ ).

\section{Discussion}

5.1. Accuracy of the TSM for surface flux estimation under Mediterranean semiarid conditions

Accurate estimation of surface fluxes in semiarid and sparsely vegetated areas is a particularly challenging task, more so when the latent heat flux is very low due to the strong water limitations (Fig. 1), such as in Mediterranean drylands (Domingo et al., 2011). In this article, we have shown that under these conditions, the TSM of Norman et al. (1995) was accurate for estimating $R n$ and $H$ fluxes, but not for $L E$ even using measured $G$ to reduce uncertainties affecting residually estimated $L E$.

Agreement between $R n$ ground observations and TSM model estimates was similar for the four TSM versions tested (parallel and series; with and without iteration) with overestimates showing a mean absolute percentage error (MAPE) of 12-13\% (Table 4). This level of accuracy is satisfactory considering that only field measurements of incoming irradiance were used, and that the uncertainty of field measurements 
TSM with iteration (using $T_{R}$ )
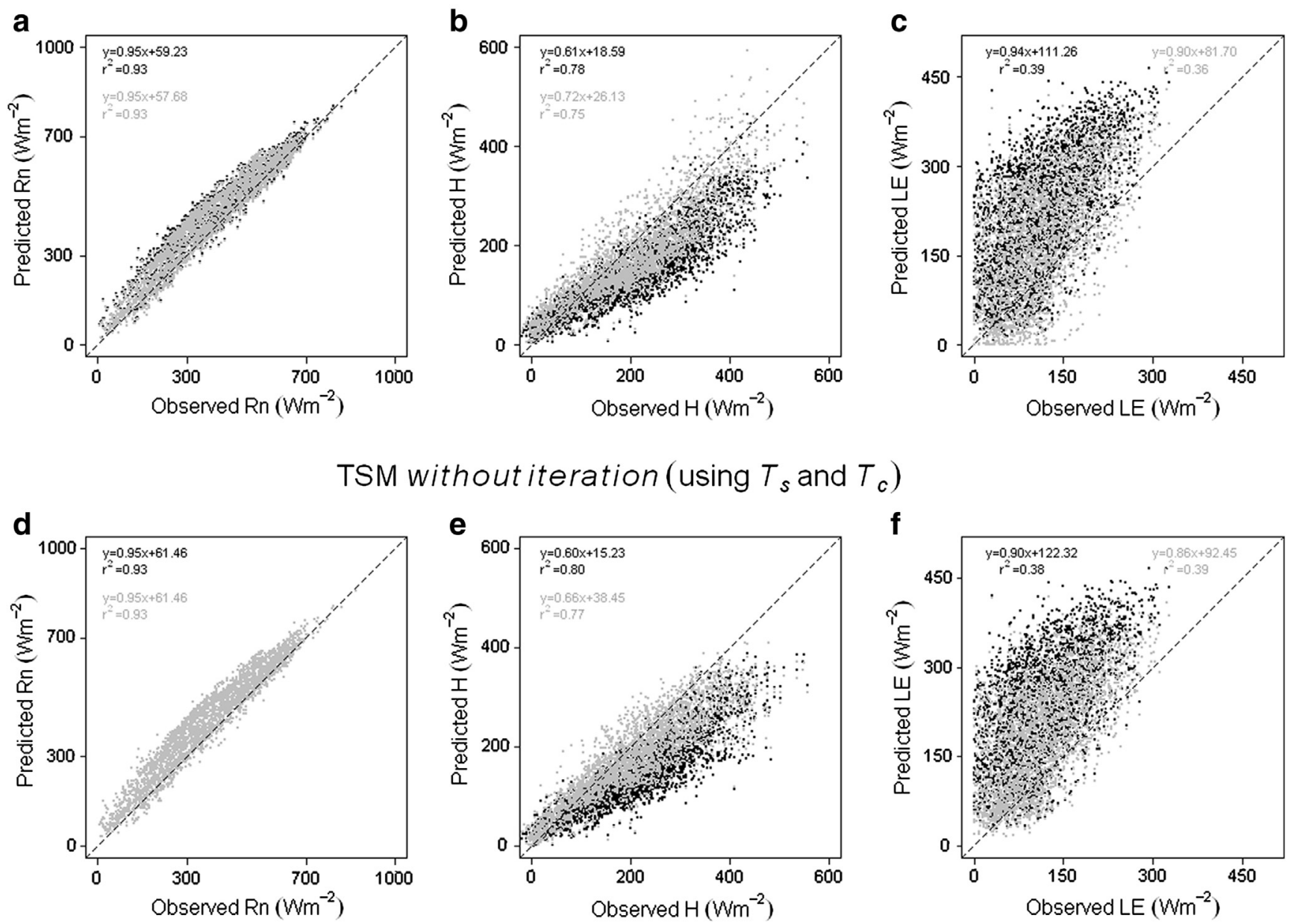

Fig. 4. Linear regressions between the surface energy fluxes estimated by the TSM with iteration (using $T_{R}$ ) (in a, b and c panels) and by the TSM without iteration (using $T_{S}$ and $T^{\prime}{ }_{c}$ ) (in d,e and f panels) versus their corresponding ground measurements: $R n, H$, and $L E$ for full dataset analyzed $(\mathrm{N}=2991)$. In grey, TSM model with parallel resistance approach $\left(\operatorname{TSM}_{P}\right)$ and in black, series resistance approach $\left(T S M_{S}\right)$. Dashed line is the 1:1 line.

of $R n$ is from 5 to $10 \%$ (Kustas \& Norman, 1996). Similar level of accuracy has been reported by others authors (13\%) in semiarid cotton croplands (Colaizzi et al., 2012c) who included specific modifications for radiation modelling in row crops (Colaizzi et al., 2012b) and in semiarid shrublands using ASTER reflectance for clear-sky conditions with errors below 8\% (Garcia et al., 2008).

$H$ estimated accuracy ranged from 23 to $34 \%$ depending on the model version (Table 4). This error is not unreasonable, bearing in mind the mismatch between the footprint of the infrared radiometers and the flux measurement area, with a spatial heterogeneity within the footprint area in $T_{R}$ and vegetation greenness around $4 \%$ for both variables (Tables 2 and 3). Despite of that, it is remarkable that the error in $H$ is not significantly higher than the 10\% to $30 \%$ uncertainty affecting turbulent flux measurement by Eddy Covariance (Twine et al., 2000) which happens to be $20 \%$ in our study site. This level of accuracy in $H$ is similar to that found by Li et al. (2005),

Table 4

Statistics comparing net Radiation $(R n)$, sensible heat $(H)$ and latent heat $(L E)$ fluxes observed and predicted by TSM using $T_{R}$ and the iteration procedure (left) and using $T S$ and $T^{\prime} C$ without iteration (right). Results of the TSM model with parallel $\left(T S M_{P}\right)$ and series resistance $\left(T S M_{S}\right)$ approaches are shown $(\mathrm{N}=2991)$.

\begin{tabular}{|c|c|c|c|c|c|c|c|c|c|c|c|c|c|c|}
\hline \multirow[t]{3}{*}{ Flux } & \multirow{3}{*}{$\begin{array}{l}\text { Resistance } \\
\text { approach }\end{array}$} & \multirow{3}{*}{$\frac{<0>}{W m^{-2}}$} & \multicolumn{6}{|c|}{ TSM with iteration (using $T_{R}$ ) } & \multicolumn{6}{|c|}{ TSM without iteration (using $T_{s}$ and $T_{c}^{\prime}$ ) } \\
\hline & & & $<P>$ & RMSE $^{\mathrm{a}}$ & $\mathrm{MAE}^{\mathrm{b}}$ & $\mathrm{MAPE}^{\mathrm{C}}$ & $\mathrm{r}^{2}$ & $\overline{\text { Slope }}$ & $\overline{\langle P\rangle}$ & RMSE $^{\mathrm{a}}$ & $\mathrm{MAE}^{\mathrm{b}}$ & MAPE $^{\mathrm{C}}$ & $\mathrm{r}^{2}$ & Slope \\
\hline & & & $\mathrm{W} \mathrm{m} \mathrm{m}^{-2}$ & $\mathrm{~W} \mathrm{m^{-2 }}$ & $\mathrm{W} \mathrm{m^{-2 }}$ & $\%$ & - & - & $\mathrm{W} \mathrm{m^{-2 }}$ & $\mathrm{W} \mathrm{m^{-2 }}$ & $\mathrm{W} \mathrm{m^{-2 }}$ & $\%$ & - & - \\
\hline \multirow[t]{2}{*}{ Rn } & $T S M_{P}$ & 375 & 412 & 58 & 46 & 12 & 0.93 & 0.95 & 418 & 62 & 49 & 13 & 0.93 & 0.95 \\
\hline & $\mathrm{TSM}_{S}$ & & 416 & 61 & 48 & 13 & 0.93 & 0.95 & & & & & & \\
\hline \multirow[t]{2}{*}{$\mathbf{H}$} & $T S M_{P}$ & 209 & 176 & 64 & 51 & 25 & 0.75 & 0.72 & 176 & 64 & 48 & 23 & 0.77 & 0.66 \\
\hline & $T S M_{S}$ & & 146 & 84 & 69 & 33 & 0.78 & 0.61 & 142 & 87 & 71 & 34 & 0.80 & 0.60 \\
\hline \multirow[t]{2}{*}{ LE } & $T S M_{P}$ & 115 & 185 & 105 & 86 & 74 & 0.36 & 0.90 & 192 & 105 & 84 & 73 & 0.39 & 0.86 \\
\hline & $T S M_{S}$ & & 220 & 130 & 110 & 95 & 0.39 & 0.94 & 227 & 135 & 115 & 99 & 0.38 & 0.90 \\
\hline
\end{tabular}

$\mathrm{a}_{<0>}>$ is the observed average.

$\mathrm{b}_{<P>}>$ is the predicted average.

${ }^{c}$ Mean absolute error $M A E=\left(\sum_{i=1}^{n}\left|P_{i}-O_{i}\right| / n\right)$

${ }^{\mathrm{d}}$ Root mean square error RMSE $=\left[\left(\sum_{i=1}^{n}\left(P_{i}-O_{i}\right)^{2} / n\right)\right]^{1 / 2}$

${ }^{\mathrm{e}}$ Mean absolute percentage error MAPE $=\frac{100}{<0}\left(\sum_{i=1}^{n}\left|P_{i}-O_{i}\right| / n\right)$, where $P_{i}$ is the model prediction, and $O_{i}$ is the observation. 


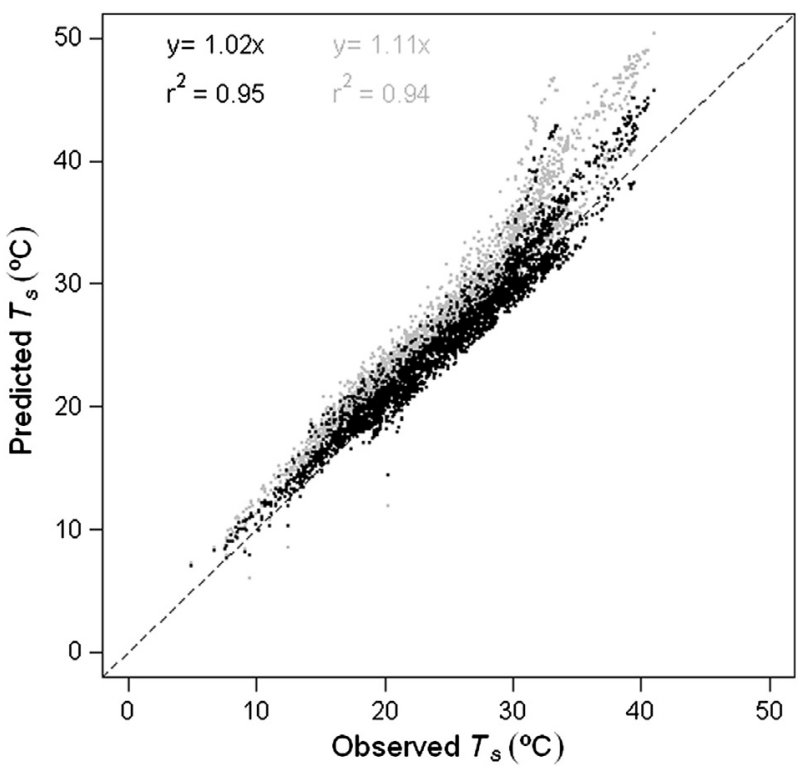

Fig. 5. Comparison of soil surface temperature ground observations and TSM with iteration output. In grey, $T_{s}$ predicted by the TSM model with the parallel resistance approach $\left(T S M_{P}\right)$ and in black, $T_{s}$ predicted by the TSM model with the series resistance approach $\left(T S M_{S}\right)(\mathrm{N}=2991)$. The dashed line is the 1:1 reference line. Root Mean Squared Error (RMSE) was $3.27^{\circ} \mathrm{C}$ and $1.67{ }^{\circ} \mathrm{C}$ for $T S M_{P}$ and $T S M_{S}$ results, respectively.

who applied the TSM in soy and corn croplands under different vegetation cover and water availability conditions, with mean relative errors of from 34 to $38 \%$. Our errors were slightly higher than the range of errors reported by previous authors in a semiarid rangeland in Arizona (19-24\%) (Norman et al., 1995; Timmermans et al., 2007; Zhan et al., 1996). However, it is important to highlight that some of these studies tested the TSM under semiarid conditions only during the wet season (Zhan et al., 1996), or using data only for short periods (3 days) (Timmermans et al., 2007). The reported tendency of the TSM to underestimate for high $H$ at our field site (Fig. $4 \mathrm{~b}$ and e) was observed at times when $H$ was higher than $L E$, which was also reported by Zhan et al. (1996) for $H$ over $300 \mathrm{~W} \mathrm{~m}^{-2}$. We observed this TSM behavior both with and without iteration (known $T_{s}$ and $T_{c}^{\prime}$ ). This shows that the tendency to underestimate is not related to limitations in the iteration approach, but could be interpreted as an indicator of an overall limitation of the TSM when $H$ is the dominant flux and also an effect to compensate for the overestimates in $R n$. It is also likely that when $H$ is the dominant flux and conditions become warmer, the surface heterogeneity within the footprint increases as was shown in Table 3, using a diurnal UAV campaign, increasing the likelihood of a mismatch between surface fluxes measured by the EC system and estimated by the TSM model (Vivoni et al., 2010).

The TSM showed a high MAE in $L E$ of $84 \mathrm{~W} \mathrm{~m}^{-2}(73 \%)$ to $115 \mathrm{~W} \mathrm{~m}^{-2}$ (99\%), and low linear agreement with $\mathrm{r}^{2}$ always below 0.4 (see Fig. 4c and f). French et al. (2003) also found higher errors in $L E$ estimates using the TSM in bare soils and patchy pasture lands (53\% and 30\% of relative error MAPE, respectively) than in more uniform pastures (10-16\%). Agam et al. (2010) also reported high MAE of around $65 \mathrm{~W} \mathrm{~m}^{-2}$ in $L E$ estimates under natural semiarid conditions with high vapor pressure deficit and low $L A I$ using an initial $\alpha_{P T}$ of 1.3. They suggested that the reduction of the initial value of $\alpha_{P T}$ used in the iteration could be consider as a possible solution to reduce $L E$ errors in the TSM under such conditions. However, our results show that similar errors affecting $L E$ were found using the TSM without iteration with no Priestley-Taylor assumption. This points out that other factors different to those related with the iteration should be causing the TSM derived LE errors. Modelling $L E$ at Mediterranean water-stressed sites like ours, where 15-min $L E$ observations are within the range of EC closure errors during several days (García et al., 2013) is challenging. As the TSM estimates $L E$ as a residual of the energy balance equation, biases from $H, R n$ and $G$ might accumulate in the $L E$ estimates and higher non-systematic errors could be expected (Kalma et al., 2008). In the present work measurements of $G$ flux were here used to reduce uncertainties affecting $L E$, because modelled $G$ from Eq. (4), even using a site calibrated $c_{g}$ value $\left(c_{g}=0.16\right)$, resulted in considerable errors $\left(r^{2}=0.52\right.$ and MAPE of $30 \%$, results not shown). Even though, the effect of a slight overestimation of $R n$ and underestimation of $H$ strongly affected $L E$ predictions which were hence overestimated in our semiarid site. Furthermore, a residual-LE closure was used for validation following the
$T S M_{S}$
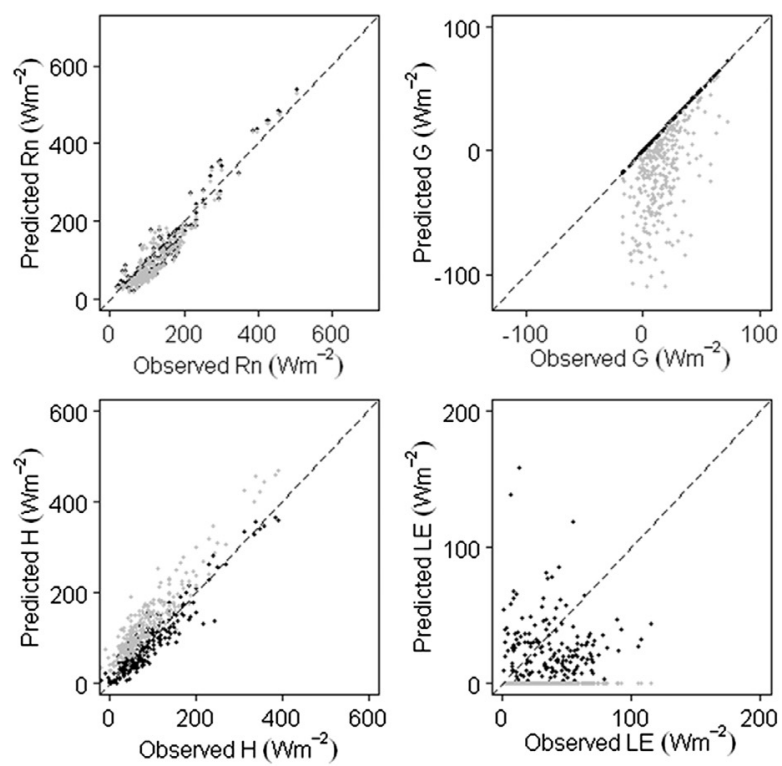

$T S M_{P}$
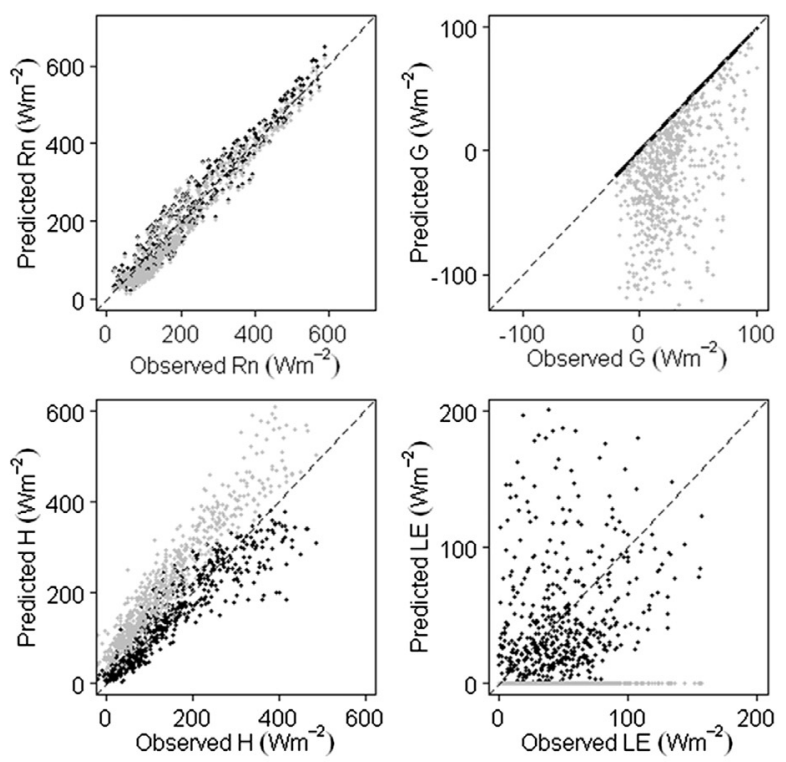

Fig. 6. Linear regressions of estimated surface fluxes by $T_{S} M_{P}$ (left) and $T S M_{S}$ (right) using measured $T_{S}$ and derived $T^{\prime}{ }_{c}$ without iteration (in black) and using $T_{R}$ and with iteration (in grey) over their corresponding ground measurements: a) $R n, \mathrm{~b}) \mathrm{G}, \mathrm{c}) \mathrm{H}, \mathrm{d}$ ) $L E$ for those observations when iteration failed using $T S M_{P}(\mathrm{~N}=668)$ or using $T S M_{S}(\mathrm{~N}=292$ ). Dashed line is the1:1 line. 
conclusions of previous authors (see Section 3.5). Therefore, uncertainty of observed $L E$ on one hand and errors in estimating $R n$ and $H$ on the other could explain the wide scatter in the $L E$ scatterplots (Fig. 4c and f). Other models tested to estimate daily $L E$ at the same field site also provide low correlations: $r^{2}$ of 0.33 to 0.49 using a Penman-Monteith model (Morillas et al., submitted for publication) and $r^{2}=0.57$ using a Priestley-Taylor model (García et al., 2013).

\subsection{Practical aspects for use of the TSM in Mediterranean drylands}

Even though the parallel resistances version of the TSM $\left(T_{S M}\right)$ was originally recommended for sparsely vegetated semiarid regions and the series resistances version $\left(T S M_{S}\right)$ for more densely vegetated regions (Kustas \& Norman, 1999b; Norman et al., 1995), results of testing both versions under a variety of conditions have been ambivalent (Kustas \& Norman, 1997, 1999a; Li et al., 2005; Zhan et al., 1996). Therefore, there is not yet a general agreement on which TSM version should be selected in each case. In this paper, the two resistance approaches to estimate surface energy fluxes under natural semiarid Mediterranean conditions were compared, and in agreement with Li et al. (2005) and Zhan et al. (1996), no strong differences were found between fluxes from the two approaches. However, the overall errors for $H$ and $L E$ fluxes were slightly lower ( $10 \%$ and $\sim 20 \%$ respectively) with the parallel resistance approach than the series (Table 4) for the TSM with and without iteration. Some differences between the series and the parallel approaches were only noticeable with TSM with iteration (Fig. $4 \mathrm{~b}$ and c). In this case, the series approach showed a stronger tendency to underestimate $H$, whereas the parallel schemes sometimes also overestimated $H$, showing a better general tendency ( slope $=0.61$ vs. slope $=0.72$ ), but slightly lower explained variance than the series approach $\left(r^{2}=0.75\right.$ vs. $r^{2}=0.78$ ) (Table 4 and Fig. 4 ). Underestimates of $H$ have also been found in agricultural areas toward the end of the wet season using the series version of the TSM when non-transpiring plant components or senescent leaves increased (Colaizzi et al., 2012a; French et al., 2007). Limitations affecting the design of the $T S M_{S}$ for partitioning of soil-canopy fluxes based on the Priestley-Taylor assumption under high senescent vegetation conditions were suggested by these authors as possible explanation. Considering that accumulation of senescent leaves in the canopy is a typical characteristic of perennial grasslands like our field site, in the present study we accounted for the variation of the green canopy fraction $\left(f_{G}\right)$ and the reduction of $\alpha_{P T}$ was allowed in the iterative procedure (See Section 2). However systematic underestimation of $H$ flux from $T S M_{S}$ was still observed at high observed $H$ rates, when senescent components are expected to be higher, and similar tendency was also observed using the $T_{S M} M_{S}$ run without iteration. Colaizzi et al. (2012c) also obtained overestimates of evapotranspiration, which should be derived from underestimates of $H$, for both TSM versions with or without iteration when canopy contained non transpiring elements. They used an alternative to the Priestley-Taylor equation based on Penman-Monteith and despite of the fact that uncertainties were reduced, overestimates in $L E$ were still found. They attributed those errors to downward bias in measurements of $T_{R}$ and $T_{c}$ with field infrared thermometers viewing a greater proportion of the top and greener part of the canopy colder than the whole canopy contained a higher proportion of non transpiring elements. In our study similar errors could be affecting and producing $T_{R}$ underestimates coinciding with possible up-ward bias of $T_{s}$, as it was measured in an area slightly less shaded than the portion of bare soil area in the footprint area of $T_{R}$.

However, overestimates of $H$ using $T S M_{P}$ and iteration are related to the thermal gradient considered in the parallel resistance approach (driven by $T_{s}-T_{a}$ and $T_{c}-T_{a}$ ), which is higher than with the series resistance (driven by $T_{s}-T_{a c}$ and $T_{c}-T_{a c}$ ). This higher thermal gradient in the parallel approach results in more frequent overestimation of $H$ (Fig. $4 \mathrm{~b}$ ) and in some $L E=0$ predictions, despite observed $L E$ being of almost $150 \mathrm{~W} \mathrm{~m}^{-2}$ (Fig. 4c). Predicted $L E=0$ were also found by Kustas and Norman (1997), who attributed them to outliers in $H$ retrievals. In this regard, the series approach, due to the moderating effect of the air temperature in the canopy interface $\left(T_{a c}\right)$, was more effective in limiting an unrealistic rise in $T_{s}$, and thereby, possible overestimates of $H_{s}$ (see detailed analysis in Li et al., 2005). In our study, the series resistance was also more robust than the parallel resistance, regardless of whether the model was run with iteration or without (Fig. 4b and e). This agrees with previous analyses, in which it has been claimed that $T S M_{S}$ is more robust, and that it can therefore be applied to a wider range of environmental conditions (Kustas \& Norman, 1999a; Li et al., 2005).

The comparison of $T_{s}$ estimated from iteration and observed can also provide some insights into the accuracy of turbulent soil and canopy flux partitioning by the two resistance approaches. Partitioning seems to have been adequate with both TSM approaches when soil temperatures were below $30{ }^{\circ} \mathrm{C}$ (Fig. 5), but turned out to be more problematic at higher $T_{s}$ conditions, with both resistance schemes showing a tendency to overestimate $T_{s}$, and presumably $H_{s}$, with the $T S M_{S}$ presenting better fit and a lower $T_{S}$ bias. This seems to indicate that the series approach allowed more accurate partitioning of turbulent fluxes in our semiarid Mediterranean conditions, which might also be indicated by the higher $\mathrm{r}^{2}$ values found for $H$ estimates in compare with the parallel version. Compared to other studies, the overall errors for $T_{S}$ estimation with iteration at our site $\left(3.37{ }^{\circ} \mathrm{C}\right.$ and $1.67{ }^{\circ} \mathrm{C}$ RMSE for $T S M_{P}$ and $T S M_{S}$, respectively) were lower than in previous studies on soybean and corn crops (RMSE $\sim 4^{\circ} \mathrm{C}$ ) (Li et al., 2005) although in those cases $T_{S}$ came from the TSM run using $T_{R}$ from satellite remote sensing images.

Minor differences between TSM performance with and without iteration were found in our field site when the iteration worked properly. Those differences were more noticeable using $\operatorname{TSM}_{P}$ than $\operatorname{TSM}_{S}$, which could indicate weaker effectiveness of iteration for flux partitioning with the parallel resistance approach. More noticeable differences between observed and predicted $L E$ from the original TSM and the simplified TSM version using measured $T_{S}$ and $T_{c},(\sim 10 \%$ of difference on MAPE), were shown by Colaizzi et al. (2012c) using $T_{S M}$ in a irrigated cotton crop area. However, several differences between their work and ours regarding water availability (dryland vs. irrigated cropland), ecosystem type (grassland vs. cotton cropland), methodology used to measure $T_{s}$ and $T_{c}$ and model design (Priestley-Taylor assumption vs. Penman Monteith assumption for the initial estimation of $T_{c}$ ) make it difficult to discern the reason behind different model performance.

Finally, in evaluating the iteration procedure proposed by Norman et al. (1995), it is also important to consider iteration failed in a certain number of cases in which the TSM was accurate using $T_{s}$ and $T^{\prime}{ }_{c}$ (Fig. 6). These iteration failures could be related with the unsuitability of $\alpha_{P T}=1.3$ used to initialize the iteration in natural semiarid areas (Agam et al., 2010). The unreliability of this value could cause overestimates of initial $L E_{c}$ resulting in $L E_{s}=0$ and overestimates of $H_{s}$ from the overall energy balance which will force the iteration to reduce $G$ flux to unreliable values $(G<<0$ ) (Fig. 6). The fact that iteration failed more often using $\operatorname{TSM}_{P}$ and in a wider range of energy supply conditions $\left(0<R n<600 \mathrm{~W} \mathrm{~m}^{-2}\right.$ ) than $T_{S M}$ (mostly $R n<300 \mathrm{~W} \mathrm{~m}^{-2}$ ) can also be attributed to the moderating effect of the air temperature in the canopy interface $\left(T_{a c}\right)$ using $T_{S} M_{S}$ reducing $H_{s}$ overestimations.

\section{Conclusions}

Our analysis using aggregated soil-vegetation radiometric temperatures showed that the TSM can be applied operationally, producing reliable estimates of sensible heat flux, $H$, and net radiation, $R n$, fluxes with error levels of $\sim 30 \%$ and $\sim 10 \%$ respectively, under the wide range of environmental conditions typical of Mediterranean semiarid perennial grasslands. However, latent heat flux, $L E$, estimates were not accurate and errors ranged from 73 to $99 \%$. The residual estimation of $L E$ in the TSM has also been shown to be problematic in areas where the magnitude of the $L E$ flux is as low (average daytime $L E$ of $70 \mathrm{~W} \mathrm{~m}^{-2}$ ) as in 
our Mediterranean field site. Under these conditions, inaccuracies associated with $R n$ and $H$ fluxes from the TSM, especially the latter, showed a strong impact on $L E$ estimates. Reduction of uncertainties of temperature measurements should be addressed in order to reduce errors affecting $H$ flux and improve $L E$ estimates from the TSM under semiarid natural conditions. Methods with a lower sensitivity of surface temperature uncertainties as the Dual-Temperature-Difference (DTD) method (Kustas et al., 2012) can also be a promising alternative in this areas which will be compared in future works with the TSM.

The choice of parallel or series resistance for the TSM was revealed to be unimportant for the overall TSM performance in semiarid areas, as no significant differences between model approaches were found at our field site, nor at other natural semiarid areas tested. However, despite having slightly lower errors in $H(\sim 10 \%)$ and $L E(\sim 20 \%)$ estimates when using the parallel approach, there is some evidence of better suitability of series resistance. It seems that the effect of considering air temperature in the canopy interface with the series approach was appreciably better than with the parallel approach for separating total fluxes into canopy and soil, and also reduced the number of cases of algorithm failure. Nonetheless, in order to establish the best resistance approach for accurate partitioning of total turbulent fluxes under semiarid Mediterranean conditions, comparisons with soil and canopy fluxes measured separately must be evaluated. Regarding the effect of using a composite soil-vegetation temperature with iteration or separate canopy and soil temperatures directly, our $H$ estimates presented lower the scatter without iteration under the parallel approach $\left(r^{2}=0.77\right.$ vs. $\left.r^{2}=0.74\right)$ and a $2 \%$ of reduction in MAPE, while in the series approach the results where more robust as they did not change significantly with or without iteration. These results show the robustness of the iteration procedure, especially under the series scheme, to disaggregate composite a soil-vegetation temperature into its separate soil and vegetation components in semiarid grasslands providing good prospects for up-scaling using mono-angle remote sensing data.

\section{Acknowledgments}

This research was funded by Andalusia Regional Government projects AQUASEM (P06-RNM-01732), GEOCARBO (P08-RNM-3721), and GLOCHARID, European Union ERDF funds, with support from the Spanish Ministry of Science and Innovation CARBORAD Projects (CGL2011-27493), the Danish Council for Independent Research and Technology and Production Sciences (FTP) Grant 09-070382, and the research project RNM-6685 financed by the Regional Andalucian Government (Spain). L. Morillas received a Ph.D. research grant and funding from the Andalusia Regional Government for visiting the Institute of Geography and Geology, University of Copenhagen, in Denmark. MODIS data were obtained through the online Data Pool at the NASA Land Processes Distributed Active Archive Center (LP DAAC), USGS/Earth Resources Observation and Science Center, Sioux Falls, South Dakota (http://lpdaac.usgs.gov/get_data). The authors would like to thank Mads Olander Rasmussen for his help with emissivity corrections; Alfredo Durán Sánchez, Iván Ortíz and Olga Uclés for their invaluable help in the field work; Albert Solé-Benet for his support as the leader of the AQUASEM project and Deborah Fuldauer for correcting and improving the English language usage.

\section{Appendix A}

A Beer's law formulation was originally proposed for partitioning net radiation between the soil and vegetation (Norman et al., 1995). However, this method results in significant systematic errors for sparse canopies with relatively hot soil surfaces and some authors only recommend it for canopies with nearly full cover (Kustas \& Norman, 1999b). As an alternative for sparse canopies, a more physically sound algorithm considering the different behavior of soil and vegetation for the visible and near infrared regions of spectrum was proposed by Kustas and Norman (1999a) for retrieving $R n_{s}$ and $R n_{c}$. Such approach is based on the radiative transfer model described in Campbell and Norman (1998). This can be expressed as in Eqs. (A.1) to (A.4):

$$
\begin{aligned}
& R n_{c}=L n_{c}+\left(1-\tau_{s}\right)\left(1-\alpha_{c}\right) S \\
& R n_{s}=L n_{s}+\tau_{s}\left(1-\alpha_{s}\right) S
\end{aligned}
$$

where $S\left(\mathrm{~W} \mathrm{~m}^{-2}\right)$ is the incoming short-wave radiation, $\tau_{s}$ is solar transmittance through the canopy, $\alpha_{s}$ is soil albedo, $\alpha_{c}$ is the canopy albedo. Estimates of $\tau_{s}, \alpha_{s}$ and $\alpha_{c}$ are computed following the equations 15.4 to 15.11 in (Campbell \& Norman, 1998) and based on LAI, the reflectances and trasmittances of soil and a single leaf, and the proportion of diffuse irradiation, assuming that the canopy has a spherical leaf angle distribution.

$L n_{s}$ and $L n_{c}\left(\mathrm{~W} \mathrm{~m}^{-2}\right)$ are the net soil and canopy long-wave radiation, respectively, estimated using the following expression:

$$
\begin{aligned}
& L n_{c}=\left[1-\exp \left(-k_{L} \Omega L A I\right)\right]\left[L_{s k y}+L_{s}-2 L_{c}\right] \\
& L n_{s}=\exp \left(-k_{L} \Omega L A I\right) L_{s k y}+\left[1-\exp \left(-k_{L} \Omega L A I\right)\right] L_{c}-L_{s}
\end{aligned}
$$

where $k_{L}\left(k_{L} \approx 0.95\right)$ is the long-wave radiation extinction coefficient, which is similar to the extinction coefficient for diffuse radiation with low vegetation, i.e., $L A I$ lower than 0.5 (Campbell \& Norman, 1998). $\Omega$ is the vegetation clumping factor proposed by Kustas and Norman (1999a) for sparsely vegetated areas, which can be set to one when measured $L A I$ implicitly includes the clumping effect (i.e. $L A I$ from the MODIS) (Anderson et al., 1997; Norman et al., 1995; Timmermans et al., 2007), and $L_{s}, L_{c}$ and $L_{s k y}\left(\mathrm{~W} \mathrm{~m}^{-2}\right)$ are the long-wave emissions from soil, canopy and sky. The Stefan-Boltzman equation based on soil, canopy and air temperatures, and vapor pressure (Brutsaert, 1982 ) can be used to compute $L_{S}, L_{c}$ and $L_{s k y}$.

\section{References}

Abrams, M., \& Hook, S. (2002). ASTER user handbook version. Jet Propulsion Laboratory, California Institute of Technology, 135.

Agam, N., Kustas, W. P., Anderson, M. C., Norman, J. M., Colaizzi, P. D., Howell, T. A. Prueger, J. H., Meyers, T. P., \& Wilson, T. B. (2010). Application of the Priestley-Taylor approach in a two-source surface energy balance model. Journal of Hydrometeorology, $11,185-198$

Alfieri, J. G., Kustas, W. P., Prueger, J. H., Hipps, L. E., Evett, S. R., Basara, J. B., Neale, C. M U., French, A. N., Colaizzi, P., Agam, N., Cosh, M. H., Chavez, J. L., \& Howell, T. A. (2012). On the discrepancy between eddy covariance and lysimetry-based surface flux measurements under strongly advective conditions. Advances in Water Resources.

Anderson, M. C., Norman, J. M., Diak, G. R., Kustas, W. P., \& Mecikalski, J. R. (1997) A two-source time-integrated model for estimating surface fluxes using thermal infrared remote sensing. Remote Sensing of Environment, 60, 195-216.

Bastiaanssen, W. G. M., Menenti, M., Feddes, R. A., \& Holtslag, A. A. M. (1998). A remote sensing surface energy balance algorithm for land (SEBAL): 1. Formulation. Journal of Hydrology, 212-213, 198-212.

Berni, J. A. J., Zarco-Tejada, P. J., Suarez, L., \& Fereres, E. (2009). Thermal and narrowband multispectral remote sensing for vegetation monitoring from an unmanned aerial vehicle. IEEE Transactions on Geoscience and Remote Sensing, 47, 722-738.

Brutsaert, W. (1982). Evaporation into the atmosphere-Theory, history and application (pp. 299). Dordrecht, Holland: D. Reidel Publishing Company.

Bugbee, B., Monje, O., \& Tanner, B. (1996). Quantifying energy and mass transfer in crop canopies: Sensors for measurement of temperature and air velocity. Advances in Space Research, 18, 149-156.

Campbell, G. S., \& Norman, J. M. (1998). An introduction to environmental biophysics. (pp 286). New York: Springer.

Chehbouni, A., LoSeen, D., Njoku, E. G., Lhomme, J. P., Monteny, B., \& Kerr, Y. H. (1997). Estimation of sensible heat flux over sparsely vegetated surfaces. Journal of Hydrology, 189, 855-868.

Chehbouni, A., Nouvellon, Y., Lhomme, J. P., Watts, C., Boulet, G., Kerr, Y. H., Moran, M. S., \& Goodrich, D. C. (2001). Estimation of surface sensible heat flux using dual angle observations of radiative surface temperature. Agricultural and Forest Meteorology, 108, 55-65.

Choudhury, B. J. (1987). Relationships between vegetation indices, radiation absorption, and net photosynthesis evaluated by a sensitivity analysis. Remote Sensing of Environment, 22, 209-233. 
Choudhury, B. J. (1992). Multispectral satellite observations for arid land studies. ISPRS Journal of Photogrammetry and Remote Sensing, 47, 101-126.

Cleugh, H. A., Leuning, R., Mu, Q., \& Running, S. W. (2007). Regional evaporation estimates from flux tower and MODIS satellite data. Remote Sensing of Environment, 106, 285-304.

Colaizzi, P. D., Evett, S. R., Howell, T. A., Gowda, P. H., O'Shaughnessy, S. A., Tolk, J. A., Kustas, W. P., \& Anderson, M. C. (2012a). Two-source energy balance model: Refinements and lysimeter tests in the southern high plains. Transactions of the ASABE, 55, 551-562.

Colaizzi, P. D., Evett, S. R., Howell, T. A., Li, F., Kustas, W. P., \& Anderson, M. C. (2012b). Radiation model for row crops: I. Geometric view factors and parameter optimization. Agronomy Journal, 104, 225-240.

Colaizzi, P. D., Kustas, W. P., Anderson, M. C., Agam, N., Tolk, J. A., Evett, S. R., Howell, T. A., Gowda, P. H., \& O'Shaughnessy, S. A. (2012c). Two-source energy balance model estimates of evapotranspiration using component and composite surface temperatures. Advances in Water Resources, 50, 134-151.

Dash, P., Göttsche, F. M., Olesen, F. S., \& Fischer, H. (2002). Land surface temperature and emissivity estimation from passive sensor data: Theory and practice-current trends. International Journal of Remote Sensing, 23, 2563-2594.

Domingo, F., Serrano-Ortiz, P., Were, A., Villagarcía, L., García, M., Ramírez, D. A. Kowalski, A. S., Moro, M. J., Rey, A., \& Oyonarte, C. (2011). Carbon and water exchange in semiarid ecosystems in SE Spain. Journal of Arid Environments, 75, 1271-1281.

Ershadi, A., McCabe, M. F., Evans, J. P., \& Walker, J. P. (2013). Effects of spatial aggregation on the multi-scale estimation of evapotranspiration. Remote Sensing of Environment, 131, 51-62.

Fisher, J. B., Tu, K. P., \& Baldocchi, D. D. (2008). Global estimates of the land-atmosphere water flux based on monthly AVHRR and ISLSCP-II data, validated at 16 FLUXNET sites. Remote Sensing of Environment, 112, 901-919.

French, A. N., Hunsaker, D. J., Clarke, T. R., Fitzgerald, G. J., Luckett, W. E., \& Pinter, P. J., Jr. (2007). Energy balance estimation of evapotranspiration for wheat grown under variable management practices in central Arizona. Transactions of the ASABE, 50, 2059-2071.

French, A. N., Schmugge, T. J., Kustas, W. P., Brubaker, K. L., \& Prueger, J. (2003). Surface energy fluxes over El Reno, Oklahoma, using high-resolution remotely sensed data. Water Resources Research, 39, SWC31-SWC312.

Fuchs, M. (1986). Heat flux. In A. Klute (Ed.), Methods of soil analysis. Part I. Physical and meteorological methods (pp. 957-968). Madison: American Society ofAgronomy.

Gamon, J. A., Field, C. B., Goulden, M. L., Griffin, K. L., Hartley, A. E., Joel, G., Penuelas, J., \& Valentini, R. (1995). Relationships between Ndvi, canopy structure, and photosynthesis in 3 Californian vegetation types. Ecological Applications, 5, 28-41.

Garcia, M., Oyonarte, C., Villagarcia, L., Contreras, S., Domingo, F., \& Puigdefabregas, J. (2008). Monitoring land degradation risk using ASTER data: The non-evaporative fraction as an indicator of ecosystem function. Remote Sensing of Environment, $112,3720-3736$.

García, M., Sandholt, I., Ceccato, P., Ridler, M., Mougin, E., Kergoat, L., Morillas, L., Timouk, F., Fensholt, R., \& Domingo, F. (2013). Actual evapotranspiration in drylands derived from in-situ and satellite data: Assessing biophysical constraints. Remote Sensing of Environment, 131, 103-118.

Glenn, E. P., Huete, A. R., Nagler, P. L., Hirschboeck, K. K., \& Brown, P. (2007). Integrating remote sensing and ground methods to estimate evapotranspiration. Critical Reviews in Plant Sciences, 26, 139-168.

Gonzalez-Dugo, M. P., Neale, C. M. U., Mateos, L., Kustas, W. P., Prueger, J. H., Anderson, M. C., \& Li, F. (2009). A comparison of operational remote sensing-based models for estimating crop evapotranspiration. Agricultural and Forest Meteorology, 149, 1843-1853.

Hall, F. G., Huemmrich, K. F., Goetz, S. J., Sellers, P. J., \& Nickeson, J. E. (1992). Satellite remote sensing of surface energy balance: Success, failures, and unresolved issues in FIFE. Journal of Geophysical Research, 97, 19,061-19,089.

Huxman, T. E., Wilcox, B. P., Breshears, D. D., Scott, R. L., Snyder, K. A., Small, E. E., Hultine, K., Pockman, W. T., \& Jackson, R. B. (2005). Ecohydrological implications of woody plant encroachment. Ecology, 86, 308-319.

Kalma, J. D., McVicar, T. R., \& McCabe, M. F. (2008). Estimating land surface evaporation: A review of methods using remotely sensed surface temperature data. Surveys in Geophysics, 29, 421-469.

Kowalski, A. S., Anthoni, P. M., Vong, R. J., Delany, A. C., \& Maclean, G. D. (1997). Deployment and evaluation of a system for ground-based measurement of cloud liquid water turbulent fluxes. Journal of Atmospheric and Oceanic Technology, 14, 468-479.

Kustas, W. P., Alfieri, J. G., Anderson, M. C., Colaizzi, P. D., Prueger, J. H., Evett, S. R., Neale, C. M. U., French, A. N., Hipps, L. E., Chávez, J. L., Copeland, K. S., \& Howell, T. A. (2012). Evaluating the two-source energy balance model using local thermal and surface flux observations in a strongly advective irrigated agricultural area. Advances in Water Resources.

Kustas, W., \& Anderson, M. (2009). Advances in thermal infrared remote sensing for land surface modeling. Agricultural and Forest Meteorology, 149, 2071-2081.

Kustas, W. P., Humes, K. S., Norman, J. M., \& Moran, M. S. (1996). Single- and dual-source modeling of surface energy fluxes with radiometric surface temperature. Journal of Applied Meteorology, 35, 110-121.

Kustas, W. P., \& Norman, J. M. (1996). Use of remote sensing for evapotranspiration monitoring over land surfaces. Hydrological Sciences Journal, 41, 495-516.

Kustas, W. P., \& Norman, J. M. (1997). A two-source approach for estimating turbulent fluxes using multiple angle thermal infrared observations. Water Resources Research, 33, 1495-1508.

Kustas, W. P., \& Norman, J. M. (1999a). Evaluation of soil and vegetation heat flux predictions using a simple two-source model with radiometric temperatures for partial canopy cover. Agricultural and Forest Meteorology, 94, 13-29.
Kustas, W. P., \& Norman, J. M. (1999b). Reply to comments about the basic equations of dual-source vegetation-atmosphere transfer models. Agricultural and Forest Meteorology, 94, 275-278.

Li, F., Kustas, W. P., Prueger, J. H., Neale, C. M. U., \& Jackson, T. J. (2005). Utility of remote-sensing-based two-source energy balance model under low- and highvegetation cover conditions. Journal of Hydrometeorology, 6, 878-891.

Massman, W. J. (1992). Correcting errors associated with soil heat flux measurements and estimating soil thermal properties from soil temperature and heat flux plate data. Agricultural and Forest Meteorology, 59, 249-266.

McMillen, R. T. (1988). An eddy correlation technique with extended applicability to non-simple terrain. Boundary-Layer Meteorology, 43, 231-245.

Mira, M., Valor, E., Boluda, R., Caselles, V., \& Coll, C. (2007). Influence of soil water content on the thermal infrared emissivity of bare soils: Implication for land surface temperature determination. Journal of Geophysical Research F: Earth Surface, 112.

Moran, M. S., Humes, K. S., \& Pinter, P. J. (1997). The scaling characteristics of remotely-sensed variables for sparsely-vegetated heterogeneous landscapes. Journal of Hydrology, 190, 337-362.

Morillas, L. R., Villagarcía, L., García, M., Serrano-Ortiz, P., \& Domingo, F. (submitted for publication). Improving evapotranspiration estimates in Mediterranean drylands: The role of soil evaporation. Water Resources Research (submitted for publication).

Norman, J. M., \& Becker, F. (1995). Terminology in thermal infrared remote sensing of natural surfaces. Agricultural and Forest Meteorology, 77, 153-166.

Norman, J. M., Kustas, W. P., \& Humes, K. S. (1995). Source approach for estimating soil and vegetation energy fluxes in observations of directional radiometric surface temperature. Agricultural and Forest Meteorology, 77, 263-293.

Priestley, C. H. B., \& Taylor, R. J. (1972). On the assessment of surface heat flux and evaporation using large-scale parameters. Monthly Weather Review, 100, 81-92.

Rana, G., \& Katerji, N. (2000). Measurement and estimation of actual evapotranspiration in the field under Mediterranean climate: A review. European Journal of Agronomy, 13, $125-153$.

Rasmussen, M. O., Göttsche, F. M., Olesen, F. S., \& Sandholt, I. (2011). Directional effects on land surface temperature estimation from meteosat second generation for savanna landscapes. IEEE Transactions on Geoscience and Remote Sensing, 49, 4458-4468.

Reynolds, J. F., Kemp, P. R., \& Tenhunen, J. D. (2000). Effects of long-term rainfall variability on evapotranspiration and soil water distribution in the Chihuahuan Desert: A modeling analysis. Plant Ecology, 150, 145-159.

Sánchez, J. M., Caselles, V., Niclós, R., Coll, C., \& Kustas, W. P. (2009). Estimating energy balance fluxes above a boreal forest from radiometric temperature observations. Agricultural and Forest Meteorology, 149, 1037-1049.

Sánchez, J. M., Kustas, W. P., Caselles, V., \& Anderson, M. C. (2008). Modelling surface energy fluxes over maize using a two-source patch model and radiometric soil and canopy temperature observations. Remote Sensing of Environment, 112, $1130-1143$.

Santanello, J. A., \& Friedl, M. A. (2003). Diurnal covariation in soil heat flux and net radiation. Journal of Applied Meteorology, 42, 851-862.

Schmid, H. P. (1994). Source areas for scalars and scalar fluxes. Boundary-Layer Meteorology, 67, 293-318.

Schmid, H. P. (1997). Experimental design for flux measurements: Matching scales of observations and fluxes. Agricultural and Forest Meteorology, 87, 179-200.

Sobrino, J. A., Raissouni, N., \& Li, Z. L. (2001). A comparative study of land surface emissivity retrieval from NOAA data. Remote Sensing of Environment, 75, 256-266.

Timmermans, W. J., Kustas, W. P., Anderson, M. C., \& French, A. N. (2007). An intercomparison of the Surface Energy Balance Algorithm for Land (SEBAL) and the Two-Source Energy Balance (TSEB) modeling schemes. Remote Sensing of Environment, 108, 369-384.

Trigo, I. F., Peres, L. F., DaCamara, C. C., \& Freitas, S. C. (2008). Thermal land surface emissivity retrieved from SEVIRI/Meteosat. IEEE Transactions on Geoscience and Remote Sensing, 46, 307-315.

Troufleau, D., Lhomme, J. P., Monteny, B., \& Vidal, A. (1997). Sensible heat flux and radiometric surface temperature over space Sahelian vegetation. I. An experimental analysis of the kB-1 parameter. Journal of Hydrology, 188-189, 815-838.

Twine, T. E., Kustas, W. P. Norman, J. M. Cook, D. R., Houser, P. R., Meyers, T. P., Prueger, J. H., Starks, P. J., \& Wesely, M. L. (2000). Correcting eddy-covariance flux underestimates over a grassland. Agricultural and Forest Meteorology, 103, 279-300.

Villagarcía, L. (2000). Reformulación, parametrización y validación de un modelo de evapotranspiración para la vegetación dispersa. (PhD Thesis). Almeria: University of Almería (Spain), 216.

Vivoni, E. R., Watts, C. J., Rodriguez, J. C., Garatuza-Payan, J., Mendez-Barroso, L. A., \& Saiz-Hernandez, J. A. (2010). Improved land-atmosphere relations through distributed footprint sampling in a subtropical scrubland during the North American monsoon. Journal of Arid Environments, 74, 579-584.

Wang, K., \& Dickinson, R. E. (2012). A review of global terrestrial evapotranspiration: Observation, modeling, climatology, and climatic variability. Reviews of Geophysics, 50.

Webb, E. K., Pearman, G. I., \& Leuning, R. (1980). Correction of flux measurements for density effects due to heat and water vapour transfer. Quarterly Journal of the Royal Meteorological Society, 106, 85-100.

Were, A., Serrano-Ortiz, P., Moreno De Jong, C., Villagarcía, L., Domingo, F., \& Kowalski, A. S. (2010). Ventilation of subterranean CO2 and eddy covariance incongruities over carbonate ecosystems. Biogeosciences, 7, 859-867. 
Wilson, K., Goldstein, A., Falge, E., Aubinet, M., Baldocchi, D., Berbigier, P., Bernhofer, C. Ceulemans, R., Dolman, H., Field, C., Grelle, A., Ibrom, A., Law, B. E., Kowalski, A., Meyers, T., Moncrieff, J., Monson, R., Oechel, W., Tenhunen, J., Valentini, R., \& Verma, S. (2002). Energy balance closure at FLUXNET sites. Agricultural and Forest Meteorology, 113, 223-243.

Zarco-Tejada, P. J., Gonzalez-Dugo, V., \& Berni, J. A. J. (2012). Fluorescence, temperature and narrow-band indices acquired from a UAV platform for water stress detection using a micro-hyperspectral imager and a thermal camera. Remote Sensing of Environment, 117, 322-337.

Zhan, X., Kustas, W. P., \& Humes, K. S. (1996). An intercomparison study on models of sensible heat flux over partial canopy surfaces with remotely sensed surface temperature. Remote Sensing of Environment, 58, 242-256. 